\title{
Galectin-1-deficient mice are protected against Trypanosoma cruzi infection through altered neutrophil migration and production of reactive oxygen species and nitric oxide
}

Thalita Bachelli Riul ${ }^{1, *}$, Helioswilton Sales de Campos ${ }^{1, \$}$, Djalma de Souza Lima-Junior ${ }^{2}$, Ana Elisa

Caleiro Seixas Azzolini ${ }^{3}$, Cristina Ribeiro de Barros Cardoso ${ }^{1}$, Sean R. Stowell ${ }^{4}$, Richard D. Cummings $^{5}$, Yara Maria Lucisano Valim ${ }^{3}$, Marcelo Dias-Baruffi ${ }^{1, \bowtie}$

${ }^{1}$ Departamento de Análises Clínicas, Toxicológicas e Bromatológicas, Faculdade de Ciências Farmacêuticas de Ribeirão Preto, Universidade de São Paulo, Ribeirão Preto - SP, Brazil.

${ }^{2}$ Departamento de Biologia Celular e Molecular e Bioagentes Patogênicos, Faculdade de Medicina de Ribeirão Preto, Universidade de São Paulo, Ribeirão Preto - SP, Brazil.

${ }^{3}$ Departamento de Física e Química, Faculdade de Ciências Farmacêuticas de Ribeirão Preto, Universidade de São Paulo, Ribeirão Preto - SP, Brazil.

${ }^{4}$ Pathology Department, Emory University School of Medicine, Atlanta, Georgia, USA.

${ }^{5}$ Department of Surgery, Beth Israel Deaconess Medical Center, Harvard Medical School, 3 Blackfan Circle, Room 11087, Boston, MA, 02115, USA.

* Present address: Faculdade de Ciências Farmacêuticas, Alimentos e Nutrição, Universidade Federal do Mato Grosso do Sul, Campo Grande - MS, Brazil

${ }^{\ddagger}$ Present address: Instituto de Patologia Tropical e Saúde Pública, Universidade Federal de Goiás, Goiânia GO, Brazil

\section{Prof. Dr. Marcelo Dias Baruffi}

Departamento de Análises Clínicas, Toxicológicas e Bromatológicas, Faculdade de Ciências Farmacêuticas de Ribeirão Preto, Universidade de São Paulo

Avenida do Café s/ $\mathrm{n}$ - Bloco M - Sala 52 ${ }^{\mathrm{a}}$ Campus da USP - Bairro Monte Alegre

CEP 14040-903 - Ribeirão Preto - SP - Brazil

mdbaruff@fcfrp.usp.br 


\section{SUMMARY}

Trypanosoma cruzi is an intracellular parasite that causes Chagas disease that affects millions of people worldwide. Many cellular and molecular aspects of this neglected disease are not fully understood. Prior studies have shown that galectin-1 (Gal-1), a $\beta$-galactoside-binding protein that regulates leukocyte recruitment to the inflammatory site, and promotes $T$. cruzi infection, but the mechanism is unclear. Here, we report that C57BL/6 mice lacking Gal-1 (Lgals ${ }^{-/}$) exhibited lower parasitemia and higher survival rates than their wildtype (WT) counterparts when infected with $T$. cruzi Y strain. Two weeks after infection, $L g a l s 1^{-1-}$ mice displayed greater neutrophil accumulation in infection site and heart tissue than WT mice. In T. cruzi-infected $L g a l s 1^{-/}$mice, infiltrated neutrophils produced increased levels of reactive oxygen species (ROS), while macrophages and neutrophils produced increased levels of nitric oxide (NO), which reduced replication and viability of parasites in vitro and downregulated IL-1 $\beta$ production. Pharmacological inhibition of NADPH oxidase and NO synthase during early in vivo infection reversed the protective effect of Gal-1 deficiency in Lgals $^{-/}$mice. Together, our findings demonstrate that lacking Gal-1 favors neutrophil migration to the infection site and increases production of ROS and NO, thereby controlling the early steps of $T$. cruzi infection by reducing parasitemia and prolonging survival of infected mice.

KEYWORDS: Trypanosoma cruzi; galectin-1; neutrophil; reactive oxygen species.

\section{INTRODUCTION}

Trypanosoma cruzi is an obligate intracellular parasite and the etiological agent of the American trypanosomiasis or Chagas disease. More than 100 years after its identification by Carlos Chagas, this parasitic infection continues to remain a significant social and public health problem in Latin America. Chagas disease is considered a neglected tropical disease by the World Health Organization due to its high prevalence in resource poor regions of the world, including those 
located in developed countries, as well as to the scarcity of investment for the development of new therapeutic and diagnostic strategies. Recent data estimate that 70 million people live in areas at risk of infection, 57 million people are infected, and 12,000 deaths/year are caused by this anthropozoonosis (Perez-Molina \& Molina, 2018). Some factors that contribute to the persistence of T. cruzi infection include transmission forms associated with solid organ transplantation, blood transfusion, resurgence of the acute phase in immunosuppressed patients, congenital infection, and high migration of people from endemic to non-endemic regions (Lattes \& Lasala, 2014; MartinsMelo, Lima, Ramos, Alencar, \& Heukelbach, 2014).

Chagas disease is characterized by an acute phase, which is poorly detected and can appear as a self-limiting febrile illness, followed by an indeterminate/latent phase that can evolve to chronic phase often accompanied by impaired function of cardiac muscle or gastrointestinal tract (Bahia, Diniz, \& Mosqueira, 2014; Hotez, 2008; Rassi, Rassi, \& Little, 2000). Some features of acute infection, such as parasitemia, extent of initial inflammatory response, and balance of regulatory responses interfere with the likelihood of chronic infection (Borges, Araujo, Cardoso, \& Lazo Chica, 2013; Marinho, D'Imperio Lima, Grisotto, \& Alvarez, 1999).

Galectin-1 (Gal-1) is a $\beta$-galactoside-binding protein with several anti-inflammatory properties. Gal-1 suppresses neutrophil migration to infection sites or a gradient of inflammatory factors, both in vitro and in vivo (Cooper, Norling, \& Perretti, 2008; La et al., 2003; Rabinovich, Sotomayor, Riera, Bianco, \& Correa, 2000), only when inflammatory conditions are present (Auvynet et al., 2013). Human recombinant Gal-1 (hrGal-1) inhibits acute inflammation in a mouse model induced by phospholipase $\mathrm{A}_{2}$ from bee venom by decreasing neutrophil infiltration (Rabinovich et al., 2000), and suppressing interleukin-1 $\beta$-induced recruitment of polymorphonuclear cells to mice peritoneal cavity, indicating that this lectin specifically downregulates the initial steps of leukocyte-endothelium interaction (La et al., 2003). In addition, hrGal-1 inhibits neutrophil capture, rolling, and adhesion on activated endothelial monolayers in vitro (Cooper et al., 2008). Leukocyte adhesion and emigration are significantly increased in Gal-1- 
null mice inflamed with IL-1 $\beta$, as demonstrated by intravital microscopy (Cooper et al., 2008). In contrast, Gal-1 induces neutrophil migration both in vitro and in vivo in the absence of an inflammatory stimuli (Auvynet et al., 2013). Hence, although the presence of Gal-1 can favor the resolution of adverse inflammatory conditions (Rabinovich et al., 2000; Rodrigues et al., 2016; Seropian et al., 2013), it can be unfavorable in the battle against infection (Davicino et al., 2017). Nevertheless, little is known regarding the role of Gal-1 in parasite infections. A recent study demonstrated that Gal-1 negatively regulates the protective immunity against $T$. cruzi. Compared to Gal-1-null mice, wild-type mice expressing Gal-1 exhibited higher levels of immune inhibitory mediators regulated by tolerogenic dendritic cells, and increased mortality rate and muscle parasitemia (Poncini et al., 2015).

Considering that (i) Gal-1 regulates neutrophil migration to inflammatory sites, (ii) neutrophils play an important role during the early stages of parasitic infection, and (iii) innate immune responses influence the progress of $T$. cruzi infection, in the present study we aimed to examine whether Gal-1 modulates recruitment of peritoneal inflammatory leukocytes and the production of ROS and NO by these cells during the acute phase of the experimental model of $T$. cruzi intraperitoneal infection in C57BL/6 mice.

\section{RESULTS}

To address whether endogenous Gal-1 interferes with the course of acute $T$. cruzi infection, both C57BL/6 WT and Lgals1 $1^{-/}$mice were infected intraperitoneally with blood trypomastigote forms of T. cruzi. The evaluation of health parameters during the acute phase of infection revealed increased blood parasitemia at the parasitemia peak (Figure 1A) and increased mortality rate (Figure $1 \mathrm{~B}$ ) of WT mice when compared with Lgals $^{-/-}$mice. Interestingly, none of the Lgals ${ }^{-/}$ mice died during the 60-day experimental period (Figure 1B). These data indicate that the presence of endogenous Gal-1 is closely associated with enhanced susceptibility to T. cruzi infection. Quantification of the relative amount of parasite DNA in the cardiac tissue evidenced (i) a fourfold 
increase in parasite DNA levels in WT mice at 14 days of infection, when compared with Lgals $^{1^{-}}$ mice ( $\mathrm{p}<0.001)$; and (ii) the presence of low and similar levels of parasite DNA in both mice groups at 21 and 28 days of infection $(\mathrm{p}<0.05)$ (Figure $1 \mathrm{C})$.

As $L$ gals $1^{-/}$mice exhibited reduced parasitemia in blood and heart tissue during the initial weeks of infection, we characterized the type of immune cells recruited to the peritoneum and heart

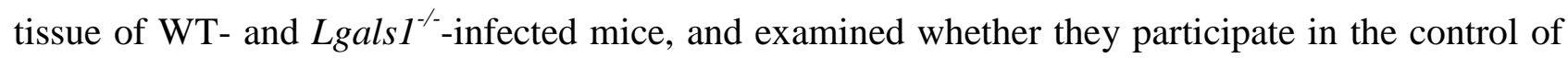
infection at its early steps. At 6, 48, and 72 hours of infection, WT and Lgals $^{-/}$mice exhibited similar profiles of peritoneal immune cells. There was increased neutrophil infiltration at 6 hours, and increased macrophage infiltration at the three experimental periods. At 24 hours, macrophage infiltration was increased in both mice groups, while neutrophil infiltration was increased only in Lgals $^{-/}$(Figure 2A). Macrophage and neutrophil infiltration in WT were greater and lower than those detected in $\operatorname{Lgals}^{-/}$, within the first 24 hours of infection. The typical morphology of macrophages, neutrophils, lymphocytes, and mast cells infiltrated into the peritoneal cavity is depicted in Figure 2B.

Quantification of interferon- $\gamma(\mathrm{IFN} \gamma)$ concentration in cardiac tissue extract revealed that its levels were augmented in $\operatorname{Lgals} 1^{-/-}$at 14 days of infection $(\mathrm{p}<0.001)$, but it decreased back to the levels detected in WT mice at 21 days of infection (Figure 2C). Determination of the relative number of neutrophils and macrophages infiltrated into cardiac tissue by measuring the activity of MPO and NAG, respectively - specific enzymes from these immune cells - at 14 days of infection demonstrated that $L$ gals $1^{-/}$had increased MPO activity (Figure 2D), whereas WT had increased NAG activity (Figure 2E). This finding is in line with the enhanced peritoneal neutrophil and macrophage infiltration in $\operatorname{Lgals} 1^{-/}$and WT, respectively (Figure 2A).

We performed histopathological analysis of cardiac tissue from WT and Lgals $^{-/}$mice at different time points of T. cruzi infection (Figure 3). The integrity of cardiac fibers from both mice groups remained virtually unchanged at 7 days of infection (Figure 3, 7d), when free parasites were still found in the bloodstream (Figure 1A). At 14 days of infection, the foci of inflammatory 
infiltrate were increased in both mice groups, and amastigote nests seem to accumulate in cardiac tissue from WT mice, but not from Lgals $1^{-/}$mice (Figure 3, 14d). Tissues from WT and Lgals $^{{ }^{-/}}$ mice clearly differed at 21 days of infection: the former still had prominent inflammatory infiltrate, while the latter resembled the tissue from non-infected animals (Figure 3, 21d and NI). Although the photomicrographs did not differentiate the immune cell types present, the aforementioned results on MPO and NAG activity (Figure 2D and 2E, respectively) estimated the relative infiltration of neutrophils and macrophages. In addition, real-time PCR analysis confirmed the highest heart parasitemia in WT mice when compared with Lgals $1^{-/}$mice (Figure 1C).

As neutrophils were the most abundantly recruited cells to the peritoneal cavity and heart tissue of $T$ cruzi-infected $L g a l s 1^{-/}$mice, we analyzed the ROS-producing capacity of these leukocytes, which is an important mechanism for the initial control of infections. Six hours after intraperitoneal infection with $T$. cruzi, leukocytes from the peritoneal cavity of WT and Lgals ${ }^{-/}$ mice were collected, washed, and stimulated with PMA and FMLP to measure ROS production through a chemiluminescence assay. All the cell preparations contained more than $80 \%$ of neutrophils. Lgals $1^{-/}$neutrophils produced more ROS than WT mice neutrophils when stimulated with PMA and fMLP (Figure 4A and B, respectively). DPI, an NADPH oxidase inhibitor, suppressed ROS production in fMLP-stimulated neutrophils from Lgals $^{-/-}$mice but not from WT mice (Figure 4B).

Considering that neutrophils are important cells of the innate immune response for the initial control of infections; Lgals $1^{-/}$mice were resistant to acute T. cruzi infection (Figure 1); presented increased neutrophil influx into the peritoneal cavity (Figure 2); and ggals $^{-/}$mice neutrophils produced more ROS than WT mice neutrophils (Figure 4A and B). Thus, we examined how inhibition of ROS production in neutrophils early recruited to the peritoneal cavity interfered with the course of acute T. cruzi infection. To this end, we administered DPI intraperitoneally to WT and $\operatorname{Lgals}^{-/}$mice during the first five days of infection. At the ninth day of infection, blood parasitemia in DPI-treated Lgals1 ${ }^{-1-}$ mice increased and reached levels similar to those detected in WT mice 
(Figure 4C). Treatment with DPI did not change blood parasitemia in WT mice. DPI-mediated suppression of ROS production increased parasitemia not only in blood but also in heart tissue of Lgals $^{-/}$mice after 14 days of infection (Figure 4D). Thus, the rapid influx of highly ROSproducing neutrophils into the infection site correlated with control of the acute $T$. cruzi infection in Lgals $1^{-/}$mice.

As IL-1 $\beta$ is one of the major cytokines that elicits ROS production in macrophages and neutrophils to help control infection (van de Veerdonk, Netea, Dinarello, \& Joosten, 2011), we measured its levels in the culture supernatant of these cells from WT and $L$ gals ${ }^{-/}$mice cultured in vitro with $T$. cruzi. Interestingly, IL-1 $\beta$ levels in cultures of peritoneal neutrophils and BMDM from WT mice were higher than those from Lgals $^{-/}$mice (Figure 5). Compared with $L g a l s 1^{-/}$mice macrophages, WT mice macrophages released higher IL-1 $\beta$ levels in response to stimulation with LPS followed or not by infection with $T$. cruzi. (Figure 5B). Hence, IL-1 $\beta$ is unlikely to mediate the enhanced ROS production in Lgals $1^{-/}$mice neutrophils and macrophages.

As macrophages and neutrophils were recruited to the peritoneal cavity of $T$. cruzi-infected WT and Lgals $^{-/-}$mice (Figure 2A), we examined their killing efficiency against the parasites during the early steps of infection. Thioglycolate-elicited macrophages from WT and $L g a l s 1^{-/}$mice were harvested and cultured with $T$. cruzi isolated from the supernatant of freshly infected LLCMK2 cells. Compared with macrophage cultures from Lgals $1^{-/}$mice, WT mice macrophages released higher number of parasites at four and five days of infection (Figure 6A) and produced less $\mathrm{NO}$ at two days of infection (Figure 6B). In the subsequent days, NO levels progressively decreased along time and reached similar levels in macrophage cultures of both WT and Lgals $1^{-/}$mice (Figure 6B).

To determine NO production by neutrophils, WT and Lgals $1^{-/}$mice were infected with $T$. cruzi and, after six hours, peritoneal cells were collected and cultured with T. cruzi for 24 hours in vitro. Levels of NO were higher (Figure 6C) and viability of the remaining parasites was lower (Figure 6D) in neutrophil cultures of $\mathrm{Lgals}^{-/-}$mice, as compared with neutrophils of WT mice. 
Finally, we examined whether treatment with the NO synthase inhibitor L-NAME at early steps (day 0 to 5) of in vivo T. cruzi infection affected parasitemia in WT and Lgals ${ }^{-/}$mice. LNAME-treated WT and Lgals $1^{-/}$mice exhibited increased blood parasitemia at nine days of infection when compared with their respective non-treated controls (Figure 6E). Blood parasitemia in L-NAME-treated Lgals1 ${ }^{-/}$mice was lower than that detected in WT mice, indicating that NO synthase inhibition enhanced parasitemia less effectively than DPI-mediated suppression of ROS production in Lgals $^{-/}$mice (Figure 4D). Together, ROS and NO production in LgalsI $^{\text {- }}$ mice correlated with control of the $T$. cruzi infection at the inoculation site, resulting in decreased parasitemia during the acute phase of this experimental infection.

\section{DISCUSSION}

Our results demonstrate that the lack of Gal-1 in Lgals $^{\text {\%- }}$ mice is associated with lower parasitemia levels and higher survival rates than their WT counterparts when infected with T. cruzi Y strain. We also observed greater neutrophil accumulation in the peritoneal cavity and in heart tissue of $L g a l s 1^{-1-}$ mice compared to WT mice. The infiltrated neutrophils in T. cruzi-infected

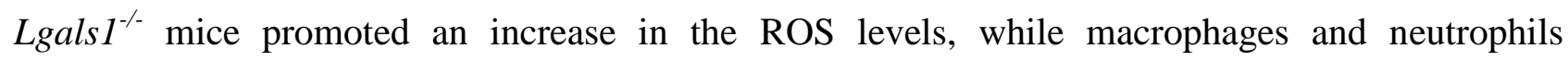
produced increased levels of nitric oxide, which limited replication and decreased viability of parasites in vitro associated to downregulated IL-1 $\beta$ production. Taken together, our findings demonstrate that a deficiency of Gal-1 suppresses the early steps of $T$. cruzi infection, reducing the

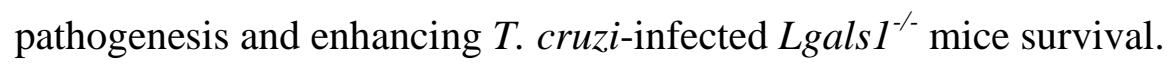

Prior studies have indicated that Gal-1 and Gal-3 may influence T. cruzi infection (Benatar et al., 2015; da Silva et al., 2017; Machado et al., 2014; Pineda, Cuervo, Fresno, Soto, \& Bonay, 2015; Poncini et al., 2015; Reignault, Barrias, Soares Medeiros, de Souza, \& de Carvalho, 2014). As we described here, the lack of Gal-1 promotes a better outcome for the experimental Chagas disease during early infection, corroborating previous a literature report that used a different $T$. cruzi strain (Poncini et al., 2015). In that study, C57BL/6 mice lacking Gal-1 infected with T. cruzi strain 
RA have low mortality rate and muscle parasitemia, probably due to the absence of Gal-1-mediated tolerogenic circuit by dendritic cells, which impairs $\mathrm{T}$ cell-dependent anti-parasite immunity (Poncini et al., 2015). The resistance of $L g a l s 1^{-/}$mice to T. cruzi infection reported by that study prompted us to investigate how the lack of Gal-1 affected the early steps of the infection at the peritoneal cavity, focusing mainly on the phagocyte-mediated early responses and neutrophil homeostasis.

Neutrophils are among the immune cells involved in the response against parasitic infections and can remove pathogens by phagocytosis, producing mediators that recruit and activate macrophages and lymphocytes, and releasing molecules that directly control pathogen growth and proliferation, such as reactive oxygen species (ROS), proteases, and neutrophil extracellular traps (NETs) (Scapini and Cassatella, 2014; Sousa et al., 2014; Luna-Gomes et al., 2014; Sousa-Rocha et al., 2015; Dey et al., 2014; Rochael et al., 2015; Koo et al., 2016; Roma et al., 2016). Nevertheless, a tight regulation of inflammatory responses by different mechanisms is essential to protect the host against $T$. cruzi infection without causing tissue damage or other chronic conditions (Chandra et al., 2002; Reyes et al., 2006; Savino et al., 2007).

Considering that the size of parasite inoculum influences the immune response and T. cruzi

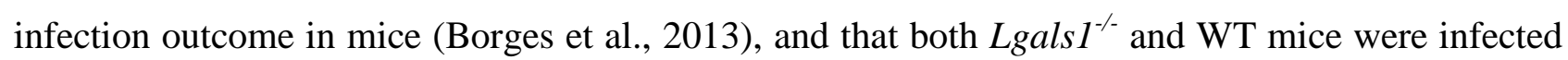
with the same inoculum but had different outcomes, we addressed whether the early response at the infection site influenced the number of parasites that reached the bloodstream and effectively infected the animal tissues. To answer this question, we infected WT and Lgals ${ }^{-/}$mice intraperitoneally with trypomastigote forms of $T$. cruzi, and analyzed the leukocyte counts in the peritoneal cavity after $6,24,48$, and 72 hours of infection. Neutrophils were the predominant leukocyte population in the peritoneal cavity of both mice groups at 6 hours of infection, but macrophages predominated at longer infection times (Figure 2A). Compared with WT mice, Lgals $1^{-}$ /- mice had higher percentage of neutrophils up to 24 hours of infection, and similar leukocyte populations at 48 and 72 hours of infection. 
Gal-1 inhibits neutrophil-endothelial cells interaction, decreasing leukocyte influx under inflammatory conditions (La et al., 2003). Neutrophils are crucial to control the first steps of different infections, including those caused by protozoan parasites. For instance, mice infected intradermically with Leishmania amazonensis promastigotes exhibit neutrophil accumulation in the lesion between 6 and $24 \mathrm{~h}$ of infection, which reduces after 72 hours (Sousa et al., 2014). Neutrophil depletion with specific monoclonal antibodies increases parasite counts and lesion development during the first week of infection with L. amazonensis (Sousa et al., 2014). Also, neutrophil depletion one day before infection with $T$. cruzi strain Tulahuén enhances blood parasitemia in BALB/c mice, but reduces blood parasitemia in C57BL/6 mice after 12 and 22 days of infection, respectively; however, it is not clear whether they differ with respect to parasite load at the infection site (Chen, Watanabe, Watanabe, \& Sendo, 2001).

Interestingly, as expected, here we demonstrated that the deficiency of endogenous Gal-1 interferes in the early steps of $T$. cruzi infection and favored neutrophil accumulation at the infectious site. Our results indicate that this event promotes a drastic reduction on parasitic load and ameliorates the outcome of experimental Chagas disease, as described under experimental conditions using low parasite inoculum (Borges et al., 2013).

In addition to higher neutrophil counts in the peritoneal cavity in comparison to WT mice, Lgals $1^{-}$mice heart tissue exhibited elevated neutrophil numbers as indicated by higher MPO activity when compared to WT mice heart tissue after 14 days of infection. In this sense, our findings on neutrophil accumulation into T. cruzi-infected mice provide partial explanation for the early control of infection, both at infection site and target organ of the infection. That effect can be explained due to Gal-1 being an endogenous agent for neutrophil homeostasis through its unique property of promoting the phagocytic removal of neutrophil in the absence of apoptosis, a phenomenon called preaparesis (Dias-Baruffi et al., 2003; Stowell, Cho, et al., 2009; Stowell, Karmakar, et al., 2009; Stowell et al., 2007; Stowell et al., 2008). 
Our findings corroborate literature reports on the importance of neutrophils to control $T$. cruzi infection. Co-cultures of $T$. cruzi-infected macrophages with neutrophils isolated from C57BL/6 mice display reduced number of trypomastigotes and increased production of TNF- $\alpha$ and NO (Luna-Gomes et al., 2014). Treatment with a selective inducible NO synthase inhibitor favors parasite growth, suggesting that NO plays an important role in parasite killing (Luna-Gomes et al., 2014). Human neutrophils stimulated with live T. cruzi or its antigens release NETs, which do not kill the parasites, but immobilize them and interfere with their infection ability (Sousa-Rocha et al., 2015). Mouse neutrophils also produce and release NETs (Etulain et al., 2015), which help to reduce T. gondii viability in vivo and in vitro (Abi Abdallah et al., 2012). Thus, the early and effective neutrophil recruitment to the peritoneal cavity and heart tissue of $\mathrm{Lgals}^{-/}$mice help to control T. cruzi infection, but the underlying mechanisms, including NETs release, will be explored in future studies.

Analysis of IFN $\gamma$ levels in heart tissue from WT and ggals $^{-/}$mice after 14 days of infection, when they presented similar inflammatory infiltrates, demonstrated that the cytokine levels were higher in Lgals $^{-/}$mice (Figure 2C). As IFN $\gamma$ is an important cytokine to control parasite replication by activating killing mechanisms in both macrophages and neutrophils (Marchi, Sesti-Costa, Ignacchiti, Chedraoui-Silva, \& Mantovani, 2014), the strong neutrophil recruitment to the heart of T. cruzi-infected Lgals $1^{-/}$mice is linked to the presence of high levels of IFN $\gamma$, which improve the control of parasitemia (Figure 1C).

Despite the well-known importance of neutrophils to control parasite infection, especially that caused by protozoans and T. cruzi (Abi Abdallah et al., 2012; Luna-Gomes et al., 2014; SousaRocha et al., 2015; Sousa et al., 2014), recruitment of neutrophils and other leukocytes must be tightly controlled to avoid exacerbation of inflammatory responses and tissue damage (Dhiman \& Garg, 2011; Paiva, Medei, \& Bozza, 2018). In this sense, we examined the profile of leukocyte recruitment to not only the peritoneal cavity but also to heart tissue of $T$. cruzi-infected WT and Lgals $1^{-/}$mice during the acute phase of infection (Figure 3). 
It is noteworthy that both WT and $L g a l s 1^{-1-}$ mice displayed similar profiles of leukocyte infiltration at 14 days of infection, but they clearly differed at 21 days of infection: the infiltrated cells appeared to be cleared from Lgals $^{-/-}$mice, but they were still present in WT mice. Although the photomicrographs did not distinguish the type of infiltrated cells at 14 days of infection, the increased levels of IFN $\gamma$ (Figure 2C) and the increased MPO activity (Figure 2 D) in the heart tissue correlated with the lower blood parasitemia in Lgals $^{-/}$mice (Figure 1C). This tightly regulated recruitment of inflammatory cells to the heart tissue, especially the neutrophil-rich infiltrate in Lgals $1^{-/}$mice, could rapidly clear the parasites that were not killed in the peritoneal cavity and reached the heart. The controlled neutrophil recruitment to the peritoneal cavity and heart tissue, associated with their clearance right after parasite control, prevent exacerbation of inflammatory responses, which could be detrimental to the host.

The fact that $\operatorname{Lgals} 1^{-/}$mice exhibited higher neutrophil infiltration into the peritoneal cavity and heart tissue, associated with lower parasitemia and longer survival rates, prompted us to investigate the role of ROS production by neutrophils in controling T. cruzi replication (Alvarez, Piacenza, Irigoin, Peluffo, \& Radi, 2004; Guinazu et al., 2010; Robinson, 2008). Compared with WT mice neutrophils, Lgals $1^{-/}$mice neutrophils produced higher levels of ROS after stimulation with the phorbol ester PMA and the tripeptide fMLP (Figure 4A and 4B, respectively). The NADPH oxidase inhibitor DPI effectively controlled ROS production in fMLP-stimulated Lgals ${ }^{-/}$ mice neutrophils, but failed to control ROS production in PMA-stimulated neutrophils from both WT and Lgals $^{-/}$mice.

To test the hypothesis that the increased ROS production in $L$ gals $1^{-/}$mice neutrophils helped to control T. cruzi infection at the infection site, we treated WT and $L g a l s 1^{-/}$mice with DPI solution ( $1 \mathrm{mg} / \mathrm{kg} /$ day, i.p.) during the first five days of infection with $T$. cruzi, and analyzed blood and heart parasite load after the fifth day of infection. At nine days of infection, DPI-treated Lgals $^{-}$ '- mice failed to control T. cruzi infection, and exhibited circulating parasite levels similar to those detected in WT mice treated or not with DPI (Figure 4C). At 14 days of infection, DPI-treated 
Lgals $^{-/}$mice and WT mice treated or not with DPI had high parasite DNA levels in heart tissue (Figure 4D). Only Lgals $1^{-/}$mice not treated with DPI exhibited significantly reduced blood parasitemia at nine days of infection (Figure 4C) and lowered parasite DNA levels at 14 days of infection (Figure 4D).

ROS are key players in the control of parasite infection, especially that caused by $T$. cruzi and Leishmania sp. (Roma et al., 2016; Santiago et al., 2012). Here we also examined the role that galectins played in ROS production, but it should be noted that Gal-3 is essential for peritoneal neutrophil ROS production and control of early $T$. gondii infection, and modulates the life span and activation of these leukocytes (Alves et al., 2010; Alves et al., 2013). However, Gal-1, through the neuropilin-1/Smad3 signaling pathway, induces myofibroblast activation, triggers ROS production, and accelerates wound healing (Lin et al., 2015). In our model, recruitment of highly ROSproducing neutrophils to the infection site and heart tissue favors the control of $T$. cruzi proliferation in Lgals $^{-/-}$mice; treatment with the NADPH oxidase inhibitor DPI during early infection in vivo mitigated such protective action absence of endogenous Gal-1.

Considering that the increased ROS production by $\operatorname{Lgals}^{-/}$mice neutrophils improved the control of acute T. cruzi infection (Figure 4), and that ROS participates in inflammasome activation and IL-1 $\beta$ production (Martinon, 2010; Tschopp \& Schroder, 2010), we examined IL-1 $\beta$ production by neutrophils and macrophages from WT and Lgals $1^{-/}$mice, cultured with trypomastigote forms of the parasite. WT mice peritoneal neutrophils released higher IL-1 $\beta$ levels than $L g a l s 1^{-/}$mice neutrophils (Figure 5A). Similarly, bone marrow-derived macrophages from WT mice, primed or not with LPS and cultured with T. cruzi, produced higher levels of IL-1 $\beta$ than $L g a l s 1^{-/}$mice macrophages (Figure 5B).

Inflammasomes are protein complexes that autocatalytically activate intracellular caspase-1, which cleaves the inactive precursors of IL-1 $\beta$ and IL-18 into bioactive cytokines. IL- $1 \beta$ production is associated with resistance against several infectious agents (van de Veerdonk et al., 2011), including Leishmania spp. (Lima-Junior et al., 2013), but it seems not to play an essential role 
against $T$. cruzi, although some studies have demonstrated its importance to fight against this parasite (Silva et al., 2013). NLRP3 inflammasome controls T. cruzi replication in macrophages via caspase-1, independent of IL-1 $\beta$ but dependent on NO production (Goncalves et al., 2013). Macrophages from T. cruzi-infected $N L R P 3^{-/-}$mice produce high basal levels of ROS, which contribute to parasite killing through an IL-1 $\beta$-independent pathway (Dey et al., 2014).

Several of our results were unexpected, including the observation that WT neutrophils and macrophages release higher levels of IL-1 $\beta$ than Lgals $1^{-/-}$leukocytes when in contact with T. cruzi (Figure 5). By contrast, WT leukocytes produced lower levels of ROS and NO than Lgals ${ }^{-/}$ leukocytes (Figures 4 and 6). Production of oxidant species is the first line of defense against $T$. cruzi before IL-1 $\beta$ production or action (Dey et al., 2014; Goncalves et al., 2013). Hence, Lgals ${ }^{-/}$ resistance to T. cruzi can be directly related to a rapid and regulated ROS and NO production.

Several studies have reported that NO controls replication of intracellular parasites, especially T. cruzi (Aliberti, Machado, Gazzinelli, Teixeira, \& Silva, 1999; Costa et al., 2006; Vespa, Cunha, \& Silva, 1994). Here we measured the levels of NO production in WT and Lgals ${ }^{-/}$ phagocytes stimulated with T. cruzi (Figure 6). Lgals $1^{\text {-/ }}$ macrophages and neutrophils were more efficient in producing NO and killing T. cruzi than the WT leukocytes (Figures 5A and 5B). To examine the role that NO production played in vivo during early T. cruzi infection, Lgals $1^{-/}$and WT mice were treated with the NO synthase inhibitor L-NAME before infection. At the ninth day of infection, L-NAME-treated Lgals $1^{-/}$and WT mice exhibited increased blood parasitemia when compared with their respective untreated controls (Figure 6E). Blood parasitemia in L-NAME-

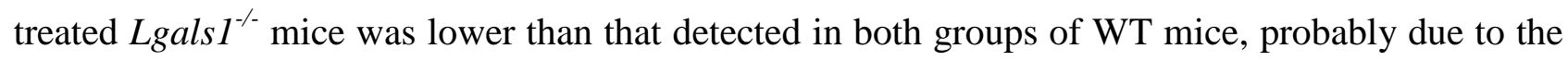
enhanced ROS production in $\operatorname{Lgals} \mathrm{I}^{-/-}$mice during early infection.

NO production can be detrimental to the mammalian host during $T$. cruzi infection, especially at chronic phase (Carvalho et al., 2012; Tatakihara et al., 2015). In addition, the lack of Gal-1 is related to stronger NO production, neutrophil infiltration, and release of inflammatory cytokines in mice infected with the fungus Histoplasma capsulatum, resulting in lower survival 
rates (Rodrigues et al., 2016). Alternatively, NO helps to regulate ROS production and protects against septic shock (Mao et al., 2013). NO inhibits the NLRP3-mediated ASC pyroptosome formation, caspase-1 activation, and IL-1 $\beta$ secretion in myeloid cells from both mice and humans. Depletion of inducible NO synthase stimulates IL-1 $\beta$ production and caspase-1 activation, which enhances NLRP3-dependent cytokine production in vivo and thereby increases mortality from LPSinduced sepsis in mice (Mao et al., 2013). Therefore, excessive IL-1 $\beta$ production not associated with tight control of NO production can culminate in death of infected mice due to exacerbation of inflammatory process. In the present study, WT leukocytes produced more IL-1 $\beta$ (Figure 5) and less ROS and NO (Figures 4 and 6, respectively) than Lgals $1^{-/}$leukocytes. In addition, WT mice exhibited higher mortality rate than $\operatorname{Lgals} 1^{-/-}$mice (Figure 1), which is probably due to a regulated NO production early during infection. Taken together, the findings reported herein suggest that rapid neutrophil recruitment associated with increased NO and ROS release protect $L g a l s 1^{-/}$mice during T. cruzi acute infection.

\section{EXPERIMENTAL PROCEDURES}

4.1 Mice and ethics. Wild type (WT) C57BL/6 mice were purchased from the Central Animal Facility at Ribeirão Preto campus of the University of São Paulo, Ribeirão Preto, SP, Brazil. C57BL/6 mice lacking Gal-1 gene $\left(\right.$ Lgals1 $\left.^{-/}\right)$were obtained from the Animal Facility at School of Pharmaceutical Sciences of Ribeirão Preto, University of São Paulo, Ribeirão Preto, SP, Brazil. WT and ggals $^{-/}$mice weighed 20-25 $\mathrm{g}$ at the moment of the experiments. The Ethics Commission on Animal Use (CEUA) at Ribeirão Preto campus of the University of São Paulo, Ribeirão Preto, SP, Brazil approved the study protocol ( $\left.\mathrm{n}^{\mathrm{o}} 08.1 .587 .53 .1\right)$.

4.2 Parasites maintenance and isolation. Trypomastigote forms of T. cruzi strain Y were maintained by serial weekly passages in Swiss mice. Blood was collected in the acute phase of infection (6 to 8 days after infection), and about $10^{6}$ trypomastigotes were freshly separated and 
used to infect sub-confluent LLC-MK2 cells (American Type Culture Collection, ATCC, CCL7.1) maintained in $75 \mathrm{~cm}^{2}$ bottles, at $37^{\circ} \mathrm{C}$ and $5 \% \mathrm{CO}_{2}$ in RPMI1640 medium containing $10 \%$ fetal bovine serum (FBS), $1 \%$ glutamine , 100 UI penicillin, $100 \mu \mathrm{g}$ of streptomycin, and $0.25 \mu \mathrm{g} / \mathrm{mL}$ of amphotericin B per mL (complete medium - all reagents from Sigma-Aldrich). To separate the trypomastigote forms from the culture, the supernatant was centrifuged at $1,000 \times g$ for 30 minutes, at $4^{\circ} \mathrm{C}$.

4.3 Mice infection, parasitemia, and survival. C57BL/6 WT and Lgals ${ }^{-1-}$ mice (six animals per group) were infected intraperitoneally with 1,000 T. cruzi trypomastigote forms freshly separated from blood of acutely infected Swiss mice, and diluted in $200 \mu \mathrm{L}$ of sterile phosphate-buffered solution (PBS). Blood parasite counts were determined as described by (Brener, 1962). Briefly, 5 $\mu \mathrm{L}$ of freshly collected tail blood were placed in a slide and covered with a coverslip to count parasites in 50 microscopic fields (400x magnification), every 2-3 days from 5 to 14 days after infection. To determine the survival rate, both infected mice groups were monitored daily until 60 days of infection.

4.4 T. cruzi DNA quantification in heart tissue by real-time PCR. Approximately $30 \mathrm{mg}$ of heart tissue from WT and $\operatorname{Lgals} 1^{-/}$mice were washed with PBS. The genomic DNA was isolated using Illustra $^{\mathrm{TM}}$ Tissue and cell genomic Prep mini spin kit (GE, USA), according to the manufacturer's instructions. The amount of recovered genomic DNA was quantified with NanoDrop ND 2000 (Thermo Scientific, USA) and stored at $-20^{\circ} \mathrm{C}$. Amplification was performed using $5 \mu \mathrm{L}$ of specific SybrGreen Master Mix reagent (Thermo Scientific), $0.35 \mu \mathrm{M}$ of each specific primer for T. cruzi genomic DNA (TCZ-F: GCTCTTGCCCACAAGGGTGC 5'-3' and 5'-TCZ R CCAAGCAGCGGATAGTTCAGG-3') (Caldas et al., 2012; Cummings \& Tarleton, 2003), 10 ng of DNA from each heart sample, and nuclease-free water sufficient to make up the reaction volume to $10 \mu \mathrm{L}$. A StepOne тм Real Time PCR System (Life Technologies, USA) apparatus was used to 
obtain $\mathrm{C}_{\mathrm{T}}$ values. DNA samples from non-infected mice were used as the negative control. A standard curve with dilution series of genomic DNA obtained from culture-derived $T$. cruzi was used to calculate the relative number of parasites in $10 \mathrm{ng}$ of sample DNA.

4.5 T. cruzi-induced peritonitis. The morphology of immune cells that migrated to the peritoneum after 6, 24, 48, and 72 hours of infection of WT and $\operatorname{Lgals} 1^{-/}$mice with 1,000 trypomastigote forms of $T$. cruzi was analyzed as follows. Further to euthanasia peritoneal cells were collected by injecting and aspirating $5 \mathrm{~mL}$ of ice-cold sterile PBS into and from the cavity, using syringe and needle. Cells were centrifuged at $300 \times g$ for 10 minutes at $4^{\circ} \mathrm{C}$, and the pellet was suspended in cold PBS. Fifty microliters of this suspension were placed on a microscope slide, centrifuged (Shandon Cytospin), dried, fixed, and stained with Panótico Rápido (Laborclin, Brazil). The percentage of each cell type was estimated by optical microscopy.

4.6 Myeloperoxidase (MPO) and N-acetyl- $\beta$-D-glucosaminidase (NAG) activity in cardiac tissue. The measurement of MPO and NAG activity, enzymes predominantly found in neutrophils and macrophages, respectively (Ayala et al., 2000), was employed to detect these cells in heart tissue. Briefly, heart tissue was homogenized in cold PBS (Ultra-Turrax disperser - IKA), centrifuged, and red blood cells in the tissue pellet were lysed by osmotic difference adding hypotonic $\mathrm{NaCl}$ solution. The homogenate was centrifuged again, and the pellet was suspended in PBS with $0.5 \%$ (w/v) of hexadecyltrimethylammonium bromide (Sigma-Aldrich) under vigorous stirring, frozen and thawed three times, and centrifuged at $10,000 \times g$ for 15 minutes at $4{ }^{\circ} \mathrm{C}$. The resulting supernatant was stored at $-80^{\circ} \mathrm{C}$ until used. To determine MPO and NAG activity. To determine MPO activity, $50 \mu \mathrm{L}$ of supernatant was mixed with $50 \mu \mathrm{L}$ of the MPO substrate 3,3',5,5'tetramethylbenzidine (Sigma-Aldrich) in a 96-well microplate. After a 30-minute incubation at $37^{\circ} \mathrm{C}$, in the dark, the reaction was stopped by adding $25 \mu \mathrm{L}$ of a $4 \mathrm{M} \mathrm{H}_{2} \mathrm{SO}_{4}$ solution to each well, and the absorbance was recorded at $450 \mathrm{~nm}$. To determine NAG activity, $25 \mu \mathrm{L}$ of supernatant was 
mixed with $25 \mu \mathrm{L}$ of $p$-nitrophenyl-2-acetamide- $\beta$-D-glucopyranoside and $100 \mu \mathrm{L}$ of citrate buffer in a 96 -well microplate. After a one-hour incubation at $37^{\circ} \mathrm{C}$, in the dark, the reaction was stopped by adding $100 \mu \mathrm{L}$ of glycine buffer to each well, and the absorbance was recorded at $405 \mathrm{~nm}$. The absorbance values at $450 \mathrm{~nm}$ and $405 \mathrm{~nm}$ were proportional to the tissue MPO and NAG activity, respectively. The activity of each enzyme per gram of tissue was obtained by dividing the absorbance values (after discounting the blank) by the total tissue mass that was initially homogenized.

\subsection{Inflammatory peritoneal neutrophils from T. cruzi-infected mice. After 6 hours of} intraperitoneal $T$. cruzi infection, neutrophils were obtained by gently injecting and aspirating $5 \mathrm{~mL}$ of cold sterile PBS into and from the peritoneal cavity of mice. The suspension was centrifuged at $300 \times g$ for 10 minutes, at $4^{\circ} \mathrm{C}$, and the neutrophil-rich pellet was treated with erythrocyte lysis buffer $\left(0.16 \mathrm{M} \mathrm{NH}_{4} \mathrm{Cl}\right.$ and $0.17 \mathrm{M}$ Tris- $\left.\mathrm{HCl}, \mathrm{pH} 7.5\right)$ for 5 minutes at $37^{\circ} \mathrm{C}$, when appropriate. After washing with ice cold PBS, cells were suspended in complete RPMI medium and viable cells were counted in a hemocytometer by trypan blue exclusion. Neutrophils obtained in this manner were routinely $>95 \%$ viable and $80-90 \%$ pure.

4.8 Reactive oxygen species (ROS) production. Chemiluminescence assay was performed according to the protocol reported by (Alves, Marzocchi-Machado, Carvalho, \& Lucisano Valim, 2003; Cheung, Archibald, \& Robinson, 1983). Inflammatory peritoneal neutrophils $\left(5 \times 10^{5}\right.$ cells $\left./ 500 \mu \mathrm{L}\right)$ obtained from T. cruzi-infected mice after 6 hours of infection were incubated with $5 \mu \mathrm{L}$ of $280 \mu \mathrm{M}$ luminol in Hanks' balanced saline solution (HBSS) for 2 min at $37^{\circ} \mathrm{C}$. Cells were then stimulated with $50 \mu \mathrm{L}$ of $10^{-7} \mathrm{M}$ phorbol 12-myristate 13-acetate (PMA, Sigma-Aldrich) or N-formylmethionyl-leucyl-phenylalanine (fMLP, Sigma-Aldrich), and chemiluminescence was recorded for 20 or 2 minutes, respectively, at $37^{\circ} \mathrm{C}$, in a luminometer (Auto Lumat LB 953 EG \& G Berthold, Bad Wildbad, Baden-Württemberg, Germany). Non-stimulated cells incubated with luminol were 
used as controls for spontaneous (basal) ROS release. Diphenyleneiodonium chloride (DPI, $10 \mu \mathrm{M}$ ), a NADPH oxidase inhibitor, was used as the negative control for ROS release in vitro (Bansal et al., 2012). The spontaneous ROS release was subtracted from the samples and the results were expressed as the integrated area of chemiluminescence profiles (area under the curve).

4.9 T. cruzi viability in inflammatory peritoneal neutrophils cultures. To assess IL-1 $\beta$ and NO production, inflammatory peritoneal neutrophils obtained from $T$. cruzi-infected WT and $L g a l s 1^{-/}$ mice, after 6 hours of infection, were washed with HBSS, suspended in complete RPMI medium $\left(5 \times 10^{5}\right.$ cells $\left./ 500 \mu \mathrm{L}\right)$, and co-cultured $\left(24\right.$ hours, $37^{\circ} \mathrm{C}$, humidified atmosphere with $\left.5 \% \mathrm{CO}_{2}\right)$ with trypomastigote forms of $T$. cruzi freshly isolated from infected LLCMK2 cell culture supernatant (5 parasites: 1 neutrophil). The well content was removed and centrifuged at $300 \times g$ for 5 minutes (to separate remaining neutrophils), and the resulting supernatant was recovered and centrifuged in a new tube at $1,000 \times \mathrm{g}$ for 30 minutes at $4^{\circ} \mathrm{C}$ (to recover the parasites). Then, the supernatant was stored at $-80{ }^{\circ} \mathrm{C}$ until determination of IL-1 $\beta$ and nitrite concentrations, while the $T$. cruzi-rich pellet was suspended in $100 \mu \mathrm{L}$ of fresh complete medium and incubated for 24 hours at $37^{\circ} \mathrm{C}$ in a humidified atmosphere with $5 \% \mathrm{CO}_{2}$, in a 96-well culture plate. To determine parasite viability, 5 $\mu \mathrm{L}$ of a $10 \mathrm{mg} / \mathrm{mL}$ solution of resazurin sodium salt (Sigma-Aldrich) prepared in PBS (pH 7) were added to each well and the plate was incubated for 4 hours at $37^{\circ} \mathrm{C}$ (Rolon, Vega, Escario, \& Gomez-Barrio, 2006). The absorbance was recorded at 570 and $600 \mathrm{~nm}$ in a SpectraMax Microplate Reader (Molecular Devices). Control wells with parasites cultured in the absence of neutrophils represent $100 \%$ T. cruzi viability.

4.10 In vivo treatment with DPI and L-NAME. In some experiments, WT and Lgals $1^{-/}$mice were treated intraperitoneally with $200 \mu \mathrm{L}$ of DPI ( $1 \mathrm{mg} / \mathrm{kg} /$ day $)$ or N $\mathrm{N}$-Nitro-L-arginine methyl ester hydrochloride (L-NAME, $100 \mathrm{mg} / \mathrm{kg} /$ day) from day 0 to day 5 after infection with $T$. cruzi. 
Solutions containing the necessary amount of each inhibitor were freshly prepared daily in sterile PBS.

4.11 Bone marrow-derived macrophages (BMDM) and IL-1 $\beta$ measurement. BMDM were obtained from WT and Lgals1 $^{-/}$mice as described by(Marim, Silveira, Lima, \& Zamboni, 2010). Briefly, bone marrow from both femurs of three animals were removed with RPMI medium supplemented with $10 \mathrm{mM}$ of L-glutamine, 30\% LCCM medium (L929-cell conditioned medium) containing macrophage colony stimulating-factor, and 10\% FBS. Cells were cultured in BD Optilux polyestirene Petri dishes $\left(4 \times 10^{6}\right.$ cells $\left./ \mathrm{mL}\right)$ for 7 days at $37{ }^{\circ} \mathrm{C}$ and $5 \% \mathrm{CO}_{2}$, with subsequent medium addition after 4 days. The macrophages were then detached from the dishes, washed with sterile PBS and cultured in a 24 -well plate $\left(5 \times 10^{5}\right.$ cells $\left./ 500 \mu \mathrm{L}\right)$ for 24 hours. Next, the cells were primed for $4 \mathrm{~h}$ with $500 \mathrm{ng} / \mathrm{mL}$ ultrapure LPS (InvivoGen). The supernatant was discharged and macrophages were infected with trypomastigote forms of $T$. cruzi freshly isolated from infected LLCMK2 cell culture supernatant (5 parasites: 1 neutrophil). After incubation $\left(24\right.$ hours, $37^{\circ} \mathrm{C}$, humidified atmosphere with $\left.5 \% \mathrm{CO}_{2}\right)$, the cell suspensions were centrifuged $\left(300 \times g, 10 \mathrm{~min}, 4{ }^{\circ} \mathrm{C}\right)$ and the resulting supernatants were collected and stored at $-80^{\circ} \mathrm{C}$. The concentration of IL-1 $\beta$ was determined using an ELISA kit (BD Biosciences).

4.12 Trypanocidal activity in infected peritoneal macrophages. WT and Lgals $1^{-/}$mice were treated with intraperitoneal injection of $1 \mathrm{~mL}$ of sterile $3 \%$ thioglycolate solution and, after four days, mice were euthanized and $5 \mathrm{~mL}$ of cold PBS were injected into and aspirated from the peritoneal cavity of the animals. The exudate was washed twice $\left(300 \times g, 5\right.$ minutes, $\left.4^{\circ} \mathrm{C}\right)$, and the resulting cell pellet was suspended in complete medium. The cells were counted, distributed into a 24-well plate $\left(5 \times 10^{5} / 500 \mu \mathrm{L} /\right.$ well $)$, incubated for 24 hours at $37^{\circ} \mathrm{C}$ in a humidified atmosphere with $5 \% \mathrm{CO}_{2}$, and washed three times with RPMI medium to remove non-adherent cells. Trypomastigote forms of $T$. cruzi obtained from infected LLCMK2 cell culture supernatant (5 parasites: 1 macrophage) were 
suspended in $500 \mu \mathrm{L}$ RPMI and added to the wells (Talvani et al., 2002). After 3 hours of incubation, the non-internalized parasites were removed by successive washes with RPMI medium. The plates were incubated for five days under the abovementioned conditions, with daily collection of culture supernatants and addition of fresh medium to the wells. Such supernatants were centrifuged $\left(1,000 \times g, 4^{\circ} \mathrm{C}, 10\right.$ minutes $)$, and the resulting pellet was suspended in $50 \mu \mathrm{L}$ of a $0.1 \%$ trypan blue/10\% formaldehyde (v/v) solution to count the released trypomastigotes in a Neubauer chamber.

4.13 NO determination. To determine NO levels in the supernatant of different cultures, the concentration of nitrite was determined by the Griess reaction (Gilliam, Sherman, Griscavage, \& Ignarro, 1993; Vespa et al., 1994). Briefly, $50 \mu \mathrm{L}$ of each culture supernatant were mixed with 50 $\mu \mathrm{L}$ of Griess reagent [1:1 (v/v) 0,1\% N-(1-naphthyl) ethylenediamine dihydrochloride (NEED, Sigma-Aldrich) in water: $1 \%$ sulfanilamide (Sigma-Aldrich) in 3\% phosphoric acid (SigmaAldrich)] in 96-well plates (Costar). After 5 minutes of incubation, the absorbance was recorded at $554 \mathrm{~nm}$ in a spectrophotometer. RPMI was used as blank reaction and a calibration curve was made with known concentrations of $\mathrm{NaNO}_{2}$ (Sigma-Aldrich) diluted in RPMI. The assay was performed in triplicate.

4.14 Statistical analysis. Experimental data were processed and analyzed using the GraphPad Prism software, version 5 for Windows (GraphPad Software Inc., USA). Two-way analysis of variance (ANOVA) combined with Bonferroni post-hoc test was used to compare three or more experimental groups, while unpaired Student $t$ test was used to compare two groups at a single point. $p<0.05$ was considered significant. 


\section{ACKNOWLEDGEMENTS}

This work was supported by The São Paulo Research Foundation (FAPESP, grant $\mathrm{n}^{\circ}$ 2010/10470-6) and Brazilian Council for Scientific and Technological Development (CNPq 312606/2019-2 and 432201/2016-5). This study was partially funded by Coordenação de Aperfeiçoamento de Pessoal de Nível Superior - Brasil (CAPES) - Código de Financiamento 001.

\section{COMPETING INTERESTS}

The authors declare no competing interests.

\section{REFERENCES}

Abi Abdallah, D. S., Lin, C., Ball, C. J., King, M. R., Duhamel, G. E., \& Denkers, E. Y. (2012). Toxoplasma gondii triggers release of human and mouse neutrophil extracellular traps. Infect Immun, 80(2), 768-777. doi:10.1128/IAI.05730-11

Aliberti, J. C., Machado, F. S., Gazzinelli, R. T., Teixeira, M. M., \& Silva, J. S. (1999). Plateletactivating factor induces nitric oxide synthesis in Trypanosoma cruzi-infected macrophages and mediates resistance to parasite infection in mice. Infect Immun, 67(6), 2810-2814.

Alvarez, M. N., Piacenza, L., Irigoin, F., Peluffo, G., \& Radi, R. (2004). Macrophage-derived peroxynitrite diffusion and toxicity to Trypanosoma cruzi. Arch Biochem Biophys, 432(2), 222-232. doi:10.1016/j.abb.2004.09.015

Alves, C. M., Marzocchi-Machado, C. M., Carvalho, I. F., \& Lucisano Valim, Y. M. (2003). Application of the chemiluminescence systems to evaluate the role of Fcgamma and complement receptors in stimulating the oxidative burst in neutrophils. Talanta, 60(2-3), 601-608. doi:10.1016/S0039-9140(03)00188-7

Alves, C. M., Silva, D. A., Azzolini, A. E., Marzocchi-Machado, C. M., Carvalho, J. V., Pajuaba, A. C., .. . Mineo, J. R. (2010). Galectin-3 plays a modulatory role in the life span and 
activation of murine neutrophils during early Toxoplasma gondii infection. Immunobiology, 215(6), 475-485. doi:10.1016/j.imbio.2009.08.001

Alves, C. M., Silva, D. A., Azzolini, A. E., Marzocchi-Machado, C. M., Lucisano-Valim, Y. M., Roque-Barreira, M. C., \& Mineo, J. R. (2013). Galectin-3 is essential for reactive oxygen species production by peritoneal neutrophils from mice infected with a virulent strain of Toxoplasma gondii. Parasitology, 140(2), 210-219. doi:10.1017/S0031182012001473

Auvynet, C., Moreno, S., Melchy, E., Coronado-Martinez, I., Montiel, J. L., Aguilar-Delfin, I., \& Rosenstein, Y. (2013). Galectin-1 promotes human neutrophil migration. Glycobiology, 23(1), 32-42. doi:10.1093/glycob/cws128

Ayala, J. M., Goyal, S., Liverton, N. J., Claremon, D. A., O'Keefe, S. J., \& Hanlon, W. A. (2000). Serum-induced monocyte differentiation and monocyte chemotaxis are regulated by the p38 MAP kinase signal transduction pathway. J Leukoc Biol, 67(6), 869-875.

Bahia, M. T., Diniz, L. D., \& Mosqueira, V. C. (2014). Therapeutical approaches under investigation for treatment of Chagas disease. Expert Opin Investig Drugs, 1-13. doi:10.1517/13543784.2014.922952

Bansal, S., Siddarth, M., Chawla, D., Banerjee, B. D., Madhu, S. V., \& Tripathi, A. K. (2012). Advanced glycation end products enhance reactive oxygen and nitrogen species generation in neutrophils in vitro. Mol Cell Biochem, 361(1-2), 289-296. doi:10.1007/s11010-011$1114-9$

Benatar, A. F., Garcia, G. A., Bua, J., Cerliani, J. P., Postan, M., Tasso, L. M., . . Gomez, K. A. (2015). Galectin-1 Prevents Infection and Damage Induced by Trypanosoma cruzi on Cardiac Cells. PLoS Negl Trop Dis, 9(10), e0004148. doi:10.1371/journal.pntd.0004148

Borges, D. C., Araujo, N. M., Cardoso, C. R., \& Lazo Chica, J. E. (2013). Different parasite inocula determine the modulation of the immune response and outcome of experimental Trypanosoma cruzi infection. Immunology, 138(2), 145-156. doi:10.1111/imm.12022 
Brener, Z. (1962). Therapeutic activity and criterion of cure on mice experimentally infected with Trypanosoma cruzi. Rev Inst Med Trop Sao Paulo, 4, 389-396.

Caldas, S., Caldas, I. S., Diniz Lde, F., Lima, W. G., Oliveira Rde, P., Cecilio, A. B., . . Bahia, M. T. (2012). Real-time PCR strategy for parasite quantification in blood and tissue samples of experimental Trypanosoma cruzi infection. Acta Trop, 123(3), 170-177. doi:10.1016/j.actatropica.2012.05.002

Carvalho, C. M., Silverio, J. C., da Silva, A. A., Pereira, I. R., Coelho, J. M., Britto, C. C., . . . Lannes-Vieira, J. (2012). Inducible nitric oxide synthase in heart tissue and nitric oxide in serum of Trypanosoma cruzi-infected rhesus monkeys: association with heart injury. PLoS Negl Trop Dis, 6(5), e1644. doi:10.1371/journal.pntd.0001644

Chen, L., Watanabe, T., Watanabe, H., \& Sendo, F. (2001). Neutrophil depletion exacerbates experimental Chagas' disease in BALB/c, but protects C57BL/6 mice through modulating the Th1/Th2 dichotomy in different directions. Eur J Immunol, 31(1), 265-275. doi:10.1002/1521-4141(200101)31:1<265::AID-IMMU265>3.0.CO;2-L

Cheung, K., Archibald, A. C., \& Robinson, M. F. (1983). The origin of chemiluminescence produced by neutrophils stimulated by opsonized zymosan. J Immunol, 130(5), 2324-2329.

Cooper, D., Norling, L. V., \& Perretti, M. (2008). Novel insights into the inhibitory effects of Galectin-1 on neutrophil recruitment under flow. J Leukoc Biol, 83(6), 1459-1466. doi:10.1189/jlb.1207831

Costa, V. M., Torres, K. C., Mendonca, R. Z., Gresser, I., Gollob, K. J., \& Abrahamsohn, I. A. (2006). Type I IFNs stimulate nitric oxide production and resistance to Trypanosoma cruzi infection. J Immunol, 177(5), 3193-3200.

Cummings, K. L., \& Tarleton, R. L. (2003). Rapid quantitation of Trypanosoma cruzi in host tissue by real-time PCR. Mol Biochem Parasitol, 129(1), 53-59. 
da Silva, A. A., Teixeira, T. L., Teixeira, S. C., Machado, F. C., Dos Santos, M. A., Tomiosso, T. C., . . . da Silva, C. V. (2017). Galectin-3: A Friend but Not a Foe during Trypanosoma cruzi Experimental Infection. Front Cell Infect Microbiol, 7, 463. doi:10.3389/fcimb.2017.00463

Davicino, R. C., Mendez-Huergo, S. P., Elicabe, R. J., Stupirski, J. C., Autenrieth, I., Di Genaro, M. S., \& Rabinovich, G. A. (2017). Galectin-1-Driven Tolerogenic Programs Aggravate Yersinia enterocolitica Infection by Repressing Antibacterial Immunity. J Immunol, 199(4), 1382-1392. doi:10.4049/jimmunol.1700579

Dey, N., Sinha, M., Gupta, S., Gonzalez, M. N., Fang, R., Endsley, J. J., . . Garg, N. J. (2014). Caspase-1/ASC inflammasome-mediated activation of IL-1beta-ROS-NF-kappaB pathway for control of Trypanosoma cruzi replication and survival is dispensable in NLRP3-/macrophages. PLoS One, 9(11), e111539. doi:10.1371/journal.pone.0111539

Dhiman, M., \& Garg, N. J. (2011). NADPH oxidase inhibition ameliorates Trypanosoma cruziinduced myocarditis during Chagas disease. J Pathol, 225(4), 583-596. doi:10.1002/path.2975

Dias-Baruffi, M., Zhu, H., Cho, M., Karmakar, S., McEver, R. P., \& Cummings, R. D. (2003). Dimeric galectin-1 induces surface exposure of phosphatidylserine and phagocytic recognition of leukocytes without inducing apoptosis. J Biol Chem, 278(42), 41282-41293. doi:10.1074/jbc.M306624200

Etulain, J., Martinod, K., Wong, S. L., Cifuni, S. M., Schattner, M., \& Wagner, D. D. (2015). Pselectin promotes neutrophil extracellular trap formation in mice. Blood, 126(2), 242-246. doi:10.1182/blood-2015-01-624023

Gilliam, M. B., Sherman, M. P., Griscavage, J. M., \& Ignarro, L. J. (1993). A spectrophotometric assay for nitrate using NADPH oxidation by Aspergillus nitrate reductase. Anal Biochem, 212(2), 359-365. doi:10.1006/abio.1993.1341

Goncalves, V. M., Matteucci, K. C., Buzzo, C. L., Miollo, B. H., Ferrante, D., Torrecilhas, A. C., . . . Bortoluci, K. R. (2013). NLRP3 controls Trypanosoma cruzi infection through a caspase- 
1-dependent IL-1R-independent NO production. PLoS Negl Trop Dis, 7(10), e2469. doi:10.1371/journal.pntd.0002469

Guinazu, N., Carrera-Silva, E. A., Becerra, M. C., Pellegrini, A., Albesa, I., \& Gea, S. (2010). Induction of NADPH oxidase activity and reactive oxygen species production by a single Trypanosoma cruzi antigen. Int J Parasitol, 40(13), 1531-1538. doi:10.1016/j.ijpara.2010.05.012

Hotez, P. J. (2008). Neglected infections of poverty in the United States of America. PLoS Negl Trop Dis, 2(6), e256. doi:10.1371/journal.pntd.0000256

La, M., Cao, T. V., Cerchiaro, G., Chilton, K., Hirabayashi, J., Kasai, K., . . Perretti, M. (2003). A novel biological activity for galectin-1: inhibition of leukocyte-endothelial cell interactions in experimental inflammation. Am J Pathol, 163(4), 1505-1515.

Lattes, R., \& Lasala, M. B. (2014). Chagas disease in the immunosuppressed patient. Clin Microbiol Infect, 20(4), 300-309. doi:10.1111/1469-0691.12585

Lima-Junior, D. S., Costa, D. L., Carregaro, V., Cunha, L. D., Silva, A. L., Mineo, T. W., .. . Zamboni, D. S. (2013). Inflammasome-derived IL-1beta production induces nitric oxidemediated resistance to Leishmania. Nat Med, 19(7), 909-915. doi:10.1038/nm.3221

Lin, Y. T., Chen, J. S., Wu, M. H., Hsieh, I. S., Liang, C. H., Hsu, C. L., . . Chen, Y. L. (2015). Galectin-1 accelerates wound healing by regulating the neuropilin-1/Smad3/NOX4 pathway and ROS production in myofibroblasts. J Invest Dermatol, 135(1), 258-268. doi:10.1038/jid.2014.288

Luna-Gomes, T., Filardy, A. A., Rocha, J. D., Decote-Ricardo, D., LaRocque-de-Freitas, I. F., Morrot, A., . . Freire-de-Lima, C. G. (2014). Neutrophils increase or reduce parasite burden in Trypanosoma cruzi-infected macrophages, depending on host strain: role of neutrophil elastase. PLoS One, 9(3), e90582. doi:10.1371/journal.pone.0090582

Machado, F. C., Cruz, L., da Silva, A. A., Cruz, M. C., Mortara, R. A., Roque-Barreira, M. C., \& da Silva, C. V. (2014). Recruitment of galectin-3 during cell invasion and intracellular 
trafficking of Trypanosoma cruzi extracellular amastigotes. Glycobiology, 24(2), 179-184. doi:10.1093/glycob/cwt097

Mao, K., Chen, S., Chen, M., Ma, Y., Wang, Y., Huang, B., . . S Sun, B. (2013). Nitric oxide suppresses NLRP3 inflammasome activation and protects against LPS-induced septic shock. Cell Res, 23(2), 201-212. doi:10.1038/cr.2013.6

Marchi, L. F., Sesti-Costa, R., Ignacchiti, M. D., Chedraoui-Silva, S., \& Mantovani, B. (2014). In vitro activation of mouse neutrophils by recombinant human interferon-gamma: increased phagocytosis and release of reactive oxygen species and pro-inflammatory cytokines. Int Immunopharmacol, 18(2), 228-235. doi:10.1016/j.intimp.2013.12.010

Marim, F. M., Silveira, T. N., Lima, D. S., Jr., \& Zamboni, D. S. (2010). A method for generation of bone marrow-derived macrophages from cryopreserved mouse bone marrow cells. PLoS One, 5(12), e15263. doi:10.1371/journal.pone.0015263

Marinho, C. R., D'Imperio Lima, M. R., Grisotto, M. G., \& Alvarez, J. M. (1999). Influence of acute-phase parasite load on pathology, parasitism, and activation of the immune system at the late chronic phase of Chagas' disease. Infect Immun, 67(1), 308-318.

Martinon, F. (2010). Signaling by ROS drives inflammasome activation. Eur J Immunol, 40(3), 616-619. doi:10.1002/eji.200940168

Martins-Melo, F. R., Lima, M. D., Ramos, A. N., Jr., Alencar, C. H., \& Heukelbach, J. (2014). Prevalence of Chagas disease in pregnant women and congenital transmission of Trypanosoma cruzi in Brazil: a systematic review and meta-analysis. Trop Med Int Health. doi:10.1111/tmi.12328

Paiva, C. N., Medei, E., \& Bozza, M. T. (2018). ROS and Trypanosoma cruzi: Fuel to infection, poison to the heart. PLoS Pathog, 14(4), e1006928. doi:10.1371/journal.ppat.1006928

Perez-Molina, J. A., \& Molina, I. (2018). Chagas disease. Lancet, 391(10115), 82-94. doi:10.1016/S0140-6736(17)31612-4 
Pineda, M. A., Cuervo, H., Fresno, M., Soto, M., \& Bonay, P. (2015). Lack of Galectin-3 Prevents Cardiac Fibrosis and Effective Immune Responses in a Murine Model of Trypanosoma cruzi Infection. J Infect Dis, 212(7), 1160-1171. doi:10.1093/infdis/jiv185

Poncini, C. V., Ilarregui, J. M., Batalla, E. I., Engels, S., Cerliani, J. P., Cucher, M. A., . .

Rabinovich, G. A. (2015). Trypanosoma cruzi Infection Imparts a Regulatory Program in Dendritic Cells and T Cells via Galectin-1-Dependent Mechanisms. J Immunol, 195(7), 3311-3324. doi:10.4049/jimmunol.1403019

Rabinovich, G. A., Sotomayor, C. E., Riera, C. M., Bianco, I., \& Correa, S. G. (2000). Evidence of a role for galectin-1 in acute inflammation. Eur J Immunol, 30(5), 1331-1339. doi:10.1002/(SICI)1521-4141(200005)30:5\&\#60;1331::AID-IMMU1331\&\#62;3.0.CO;2-H

Rassi, A., Jr., Rassi, A., \& Little, W. C. (2000). Chagas' heart disease. Clin Cardiol, 23(12), 883889.

Reignault, L. C., Barrias, E. S., Soares Medeiros, L. C., de Souza, W., \& de Carvalho, T. M. (2014). Structures containing galectin-3 are recruited to the parasitophorous vacuole containing Trypanosoma cruzi in mouse peritoneal macrophages. Parasitol Res, 113(6), 2323-2333. doi:10.1007/s00436-014-3887-8

Robinson, J. M. (2008). Reactive oxygen species in phagocytic leukocytes. Histochem Cell Biol, 130(2), 281-297. doi:10.1007/s00418-008-0461-4

Rodrigues, L. C., Secatto, A., Sorgi, C. A., Dejani, N. N., Medeiros, A. I., Prado, M. K., .. DiasBaruffi, M. (2016). Protective Effect of Galectin-1 during Histoplasma capsulatum Infection Is Associated with Prostaglandin E2 and Nitric Oxide Modulation. Mediators Inflamm, 2016, 5813794. doi:10.1155/2016/5813794

Rolon, M., Vega, C., Escario, J. A., \& Gomez-Barrio, A. (2006). Development of resazurin microtiter assay for drug sensibility testing of Trypanosoma cruzi epimastigotes. Parasitol Res, 99(2), 103-107. doi:10.1007/s00436-006-0126-y 
Roma, E. H., Macedo, J. P., Goes, G. R., Goncalves, J. L., Castro, W., Cisalpino, D., \& Vieira, L. Q. (2016). Impact of reactive oxygen species (ROS) on the control of parasite loads and inflammation in Leishmania amazonensis infection. Parasit Vectors, 9, 193. doi:10.1186/s13071-016-1472-y

Santiago, H. C., Gonzalez Lombana, C. Z., Macedo, J. P., Utsch, L., Tafuri, W. L., CampagnoleSantos, M. J., . . Vieira, L. Q. (2012). NADPH phagocyte oxidase knockout mice control Trypanosoma cruzi proliferation, but develop circulatory collapse and succumb to infection. PLoS Negl Trop Dis, 6(2), e1492. doi:10.1371/journal.pntd.0001492

Seropian, I. M., Cerliani, J. P., Toldo, S., Van Tassell, B. W., Ilarregui, J. M., Gonzalez, G. E., . . . Rabinovich, G. A. (2013). Galectin-1 controls cardiac inflammation and ventricular remodeling during acute myocardial infarction. Am J Pathol, 182(1), 29-40. doi:10.1016/j.ajpath.2012.09.022

Silva, G. K., Costa, R. S., Silveira, T. N., Caetano, B. C., Horta, C. V., Gutierrez, F. R., . . Silva, J. S. (2013). Apoptosis-associated speck-like protein containing a caspase recruitment domain inflammasomes mediate IL-1beta response and host resistance to Trypanosoma cruzi infection. J Immunol, 191(6), 3373-3383. doi:10.4049/jimmunol.1203293

Sousa-Rocha, D., Thomaz-Tobias, M., Diniz, L. F., Souza, P. S., Pinge-Filho, P., \& Toledo, K. A. (2015). Trypanosoma cruzi and Its Soluble Antigens Induce NET Release by Stimulating Toll-Like Receptors. PLoS One, 10(10), e0139569. doi:10.1371/journal.pone.0139569

Sousa, L. M., Carneiro, M. B., Resende, M. E., Martins, L. S., Dos Santos, L. M., Vaz, L. G., . . Vieira, L. Q. (2014). Neutrophils have a protective role during early stages of Leishmania amazonensis infection in BALB/c mice. Parasite Immunol, 36(1), 13-31. doi:10.1111/pim.12078

Stowell, S. R., Cho, M., Feasley, C. L., Arthur, C. M., Song, X., Colucci, J. K., . . Cummings, R. D. (2009). Ligand reduces galectin-1 sensitivity to oxidative inactivation by enhancing dimer formation. J Biol Chem, 284(8), 4989-4999. doi:10.1074/jbc.M808925200 
Stowell, S. R., Karmakar, S., Arthur, C. M., Ju, T., Rodrigues, L. C., Riul, T. B., . . Cummings, R. D. (2009). Galectin-1 induces reversible phosphatidylserine exposure at the plasma membrane. Mol Biol Cell, 20(5), 1408-1418. doi:10.1091/mbc.E08-07-0786

Stowell, S. R., Karmakar, S., Stowell, C. J., Dias-Baruffi, M., McEver, R. P., \& Cummings, R. D. (2007). Human galectin-1, -2, and -4 induce surface exposure of phosphatidylserine in activated human neutrophils but not in activated T cells. Blood, 109(1), 219-227. doi:10.1182/blood-2006-03-007153

Stowell, S. R., Qian, Y., Karmakar, S., Koyama, N. S., Dias-Baruffi, M., Leffler, H., .. . Cummings, R. D. (2008). Differential roles of galectin-1 and galectin-3 in regulating leukocyte viability and cytokine secretion. J Immunol, 180(5), 3091-3102.

Talvani, A., Machado, F. S., Santana, G. C., Klein, A., Barcelos, L., Silva, J. S., \& Teixeira, M. M. (2002). Leukotriene B(4) induces nitric oxide synthesis in Trypanosoma cruzi-infected murine macrophages and mediates resistance to infection. Infect Immun, 70(8), 4247-4253.

Tatakihara, V. L., Malvezi, A. D., Panis, C., Cecchini, R., Zanluqui, N. G., Yamauchi, L. M., .. . Pinge-Filho, P. (2015). Nitric oxide-releasing indomethacin enhances susceptibility to Trypanosoma cruzi infection acting in the cell invasion and oxidative stress associated with anemia. Chem Biol Interact, 227, 104-111. doi:10.1016/j.cbi.2014.12.024

Tschopp, J., \& Schroder, K. (2010). NLRP3 inflammasome activation: The convergence of multiple signalling pathways on ROS production? Nat Rev Immunol, 10(3), 210-215. doi:10.1038/nri2725

van de Veerdonk, F. L., Netea, M. G., Dinarello, C. A., \& Joosten, L. A. (2011). Inflammasome activation and IL-1beta and IL-18 processing during infection. Trends Immunol, 32(3), 110116. doi:10.1016/j.it.2011.01.003

Vespa, G. N., Cunha, F. Q., \& Silva, J. S. (1994). Nitric oxide is involved in control of Trypanosoma cruzi-induced parasitemia and directly kills the parasite in vitro. Infect Immun, 62(11), 5177-5182. 


\section{LEGENDS TO FIGURES}

Figure 1 - Lack of endogenous Gal-1 increases mice resistance against T. cruzi acute infection.

(A) Blood parasitemia, (B) Survival rate, and (C) Relative amount of parasites in cardiac tissue (determined by quantitative real-time PCR) from C57BL/6 wild-type (WT) and Lgals $^{\text {/- }}$ mice infected intraperitoneally with trypomastigote forms of $T$. cruzi strain Y. Results are expressed as mean \pm standard deviation $(\mathrm{n}=6) .{ }^{* * *} p<0.001,{ }^{*} p<0.01$ and $* p<0.05$ (unpaired Student $t$ test). 
Figure 2 - Wild-type and $\operatorname{Lgals}{ }^{-/-}$mice acutely infected with $T$. cruzi differ with respect to the cell migration profile into the peritoneal cavity and heart tissue. (A) Relative population of immune cells in the peritoneal cavity determined by differential count, after $6,24,48$, and 72 hours of infection. (B) Photomicrograph of a typical macrophage (M $\Phi)$, neutrophil (Ne), lymphocyte (L), and mast cell (Ma) obtained from peritoneal cavity. 1000x magnification. (C) IFN- $\gamma$ concentration in heart tissue extract after 14 and 21 days of infection. Determination of (D) myeloperoxidase (MPO) and (E) N-acetyl- $\beta$-D-glucosaminidase (NAG) activity to estimate the presence of neutrophils and macrophages in heart tissue after 14 days of infection. Results are expressed as mean \pm standard deviation $(\mathrm{n}=4-6) .{ }^{*} p<0.05 ; * * p<0.01 ; * * * p<0.001$ (unpaired Student $t$ test). 


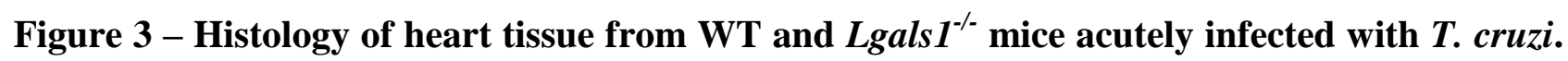
Photomicrographs of representative sections of cardiac tissues from WT and $L g a l s 1^{-/}$mice collected, processed, and analyzed after 7, 14, and 21 days of infection $(7 \mathrm{~d}, 14 \mathrm{~d}$, and 21d, respectively). NI: non-infected. The arrow indicates the presence of amastigotes nest. 
Figure $4-\operatorname{Lgals} 1^{--}$mice acutely infected with $T$. cruzi exhibit stronger peritoneal neutrophil ROS production and control of blood and heart parasitemia, which are reverted by DPI administration. Wild-type (WT) and $L g a l s 1^{-/}$mice were infected intraperitoneally with $T$. cruzi and, after 6 hours of infection, peritoneal cells (>80\% neutrophils) were collected and stimulated with (A) PMA (phorbol 12-myristate 13- acetate) or (B) fMLP (N-formyl-met-leu-phe) to produce ROS, which were detected by the luminol-enhanced chemiluminescence assay. Each bar in (A) and (B) represents a triplicate experiment with pooled cells. Parasitemia in (C) blood and (D) heart tissue was determined after intraperitoneal treatment with DPI during the first five days of infection. T. cruzi DNA load in mice heart tissues was determined by quantitative real-time PCR. Each bar in (C) and (D) represents mean \pm standard deviation ( $n=6$ animals). DPI: Diphenyleneiodonium chloride (an NADPH-oxidase inhibitor). **p $<0.01$; *** $p<0.001$ (unpaired Student's $t$ test; twoway ANOVA combined with Bonferroni post-hoc test). 


\section{Figure 5 - Peritoneal cells and bone marrow-derived macrophages from $T$. cruzi-infected}

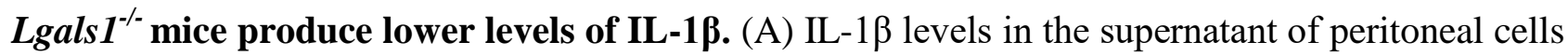
(>80\% neutrophils) cultured with $T$. cruzi for 24 hours. (B) IL-1 $\beta$ levels in the supernatant of bone marrow-derived macrophages primed or not with LPS for 4 hours and further cultured with T. cruzi for 24 hours. The cells used in (A) and (B) were collected from wild-type (WT) and $\mathrm{Lgals} 1^{-/}$mice infected intraperitoneally with T. cruzi for 6 hours. Medium: control cells, LPS: lipopolyssacharide from E. coli-stimulated cells, Tc: T. cruzi. Results are expressed as mean \pm standard deviation of three experiments with pooled cells from three mice each. ${ }^{* * *} p<0.001,{ }^{*} p<0.01$ and $* p<0.05$ (unpaired Student's $t$ test). 
Figure 6 - Nitric oxide produced by macrophages and neutrophils from Lgals $^{-/-}$mice controls T. cruzi load both in vitro and in vivo. Thioglycolate-elicited peritoneal macrophages from wildtype (WT) and Lgals ${ }^{-/}$mice were infected in vitro with T. cruzi and (A) the number of released parasites and (B) nitrite levels in culture supernatants were determined. Peritoneal cells (>80\% neutrophils) were collected from WT and Lgals $1^{-/}$mice infected with T. cruzi for 6 hours, and further cultured with $T$. cruzi for 24 hours to measure (C) nitrite levels in the supernatant and (D) the parasite viability. (E) Blood parasitemia after intraperitoneal treatment with L-NAME during the first five days of infection; *** WT $v s$ Lgals $1^{-/}$and *** Lgals $1^{-/} v s$ Lgals $1^{-/}+$L-NAME, both after 9 days of infection. Results are expressed as mean \pm standard deviation (SD) of pooled cells from 3 animals (A, B C and D) and 5 infected animals (E). ${ }^{*} p<0.05 ; * * p<0.01 ; * * * p<0.001$ (unpaired Student's t test). 

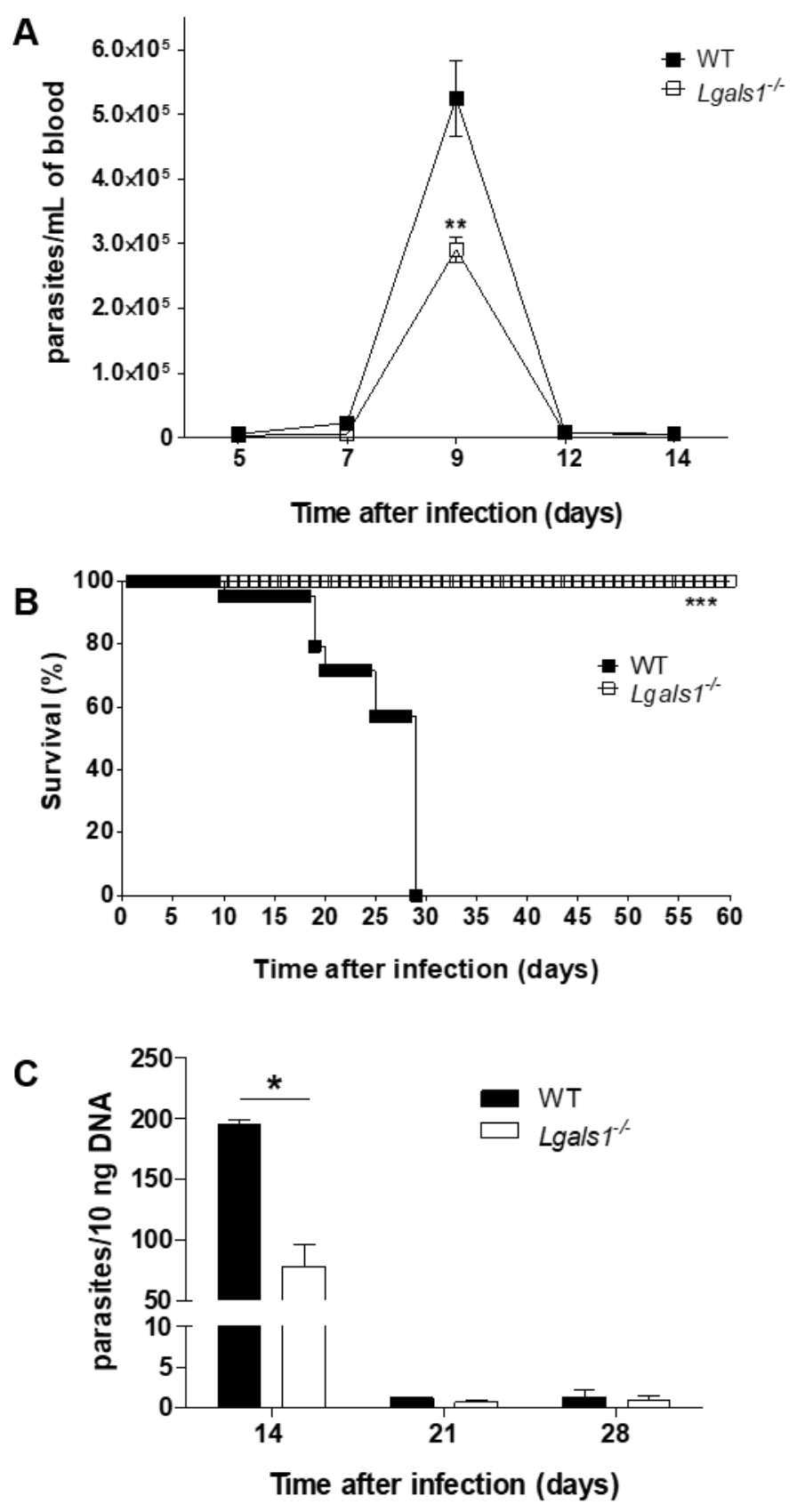
Figure 2

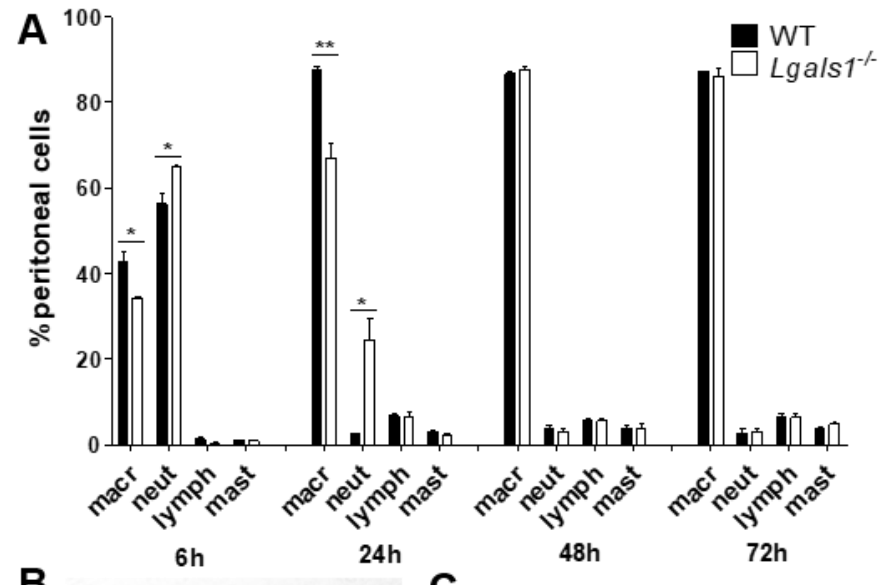

B

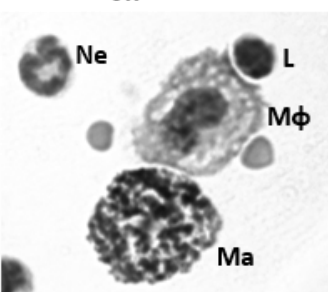

D

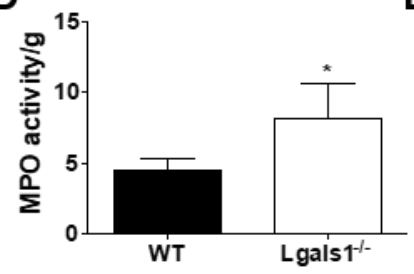

C

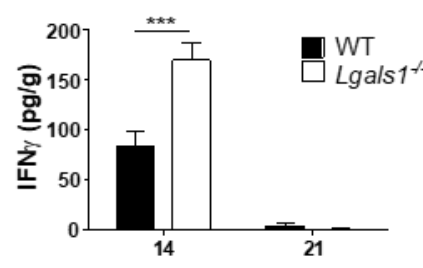

E

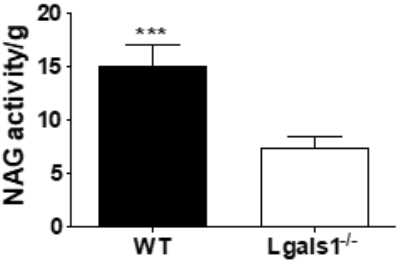


Figure 3

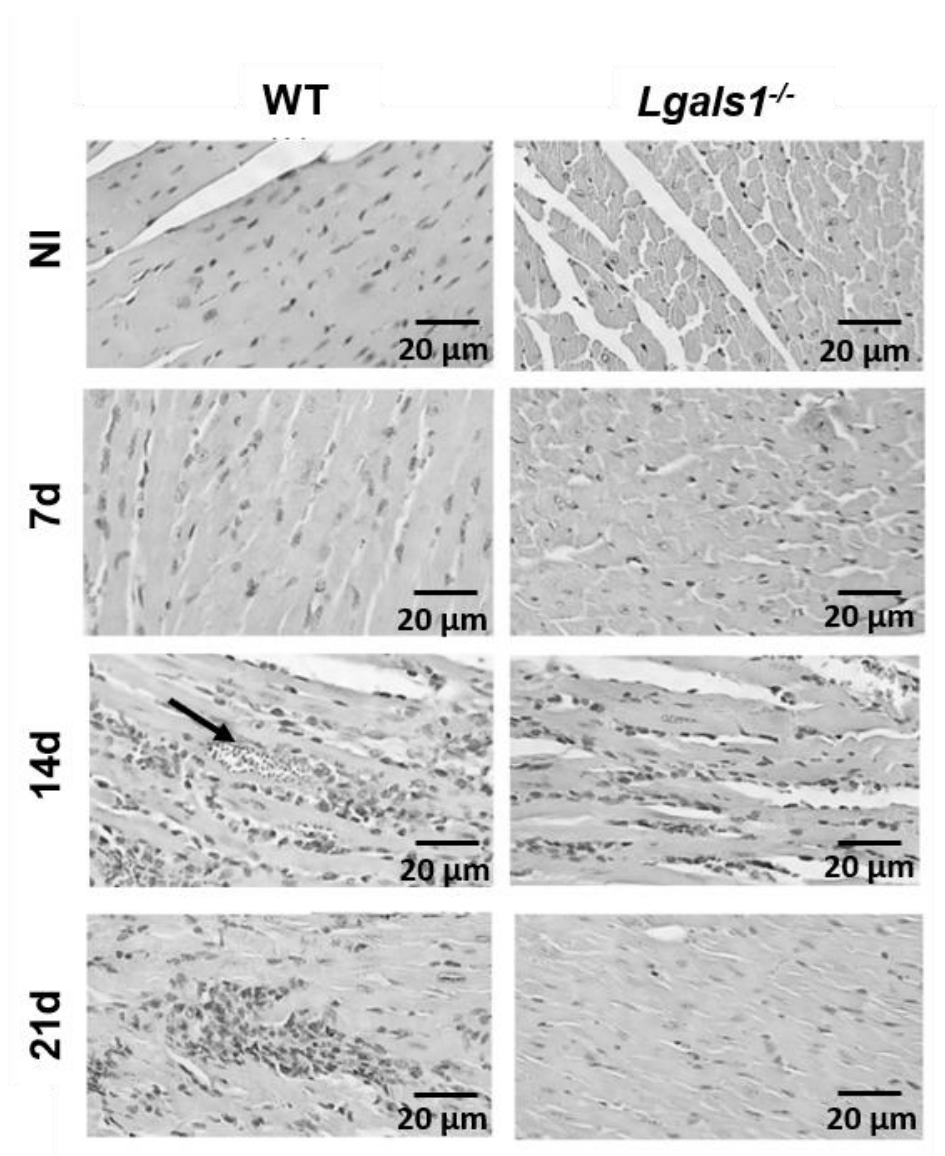


Figure 4

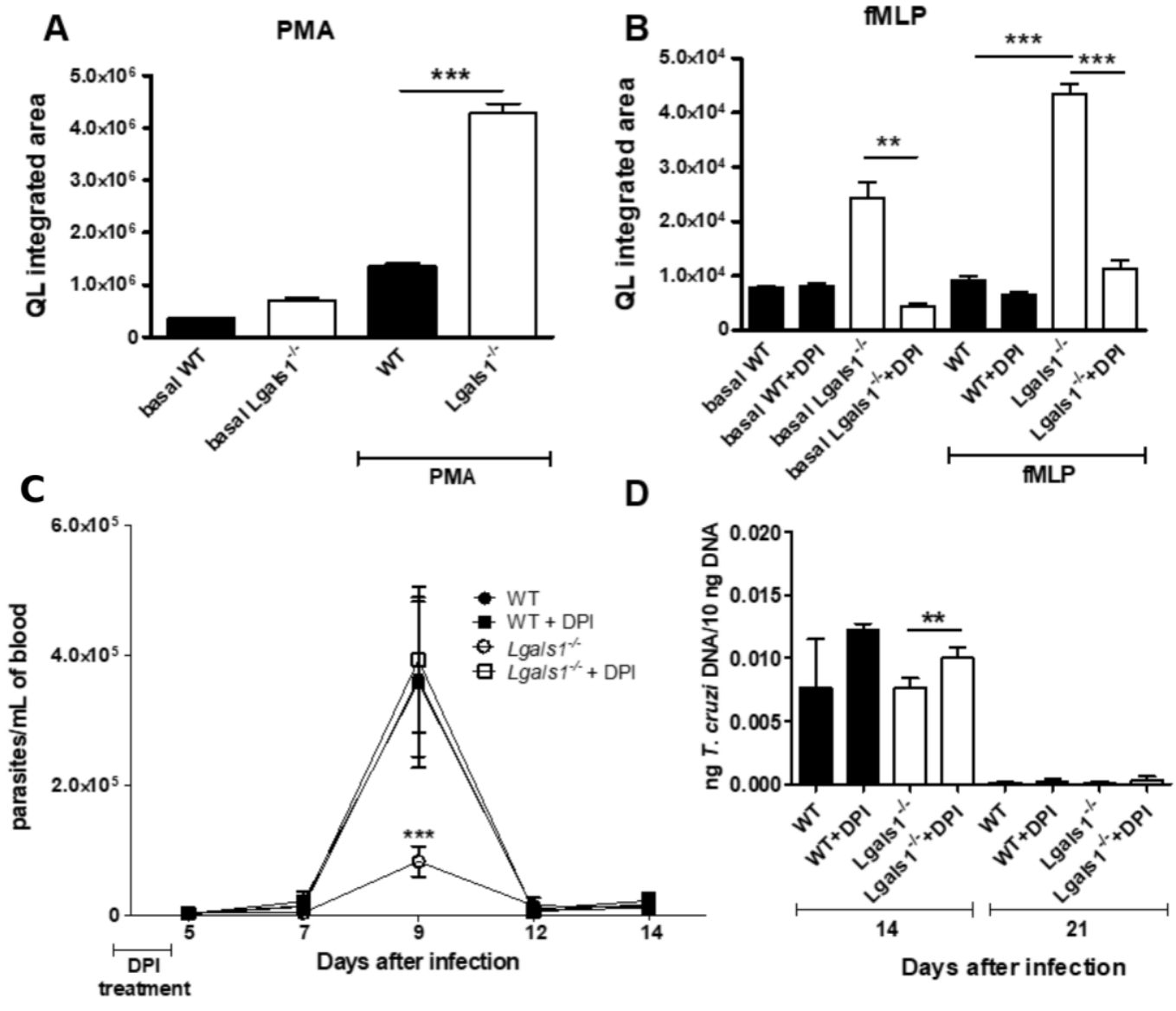


Figure 5
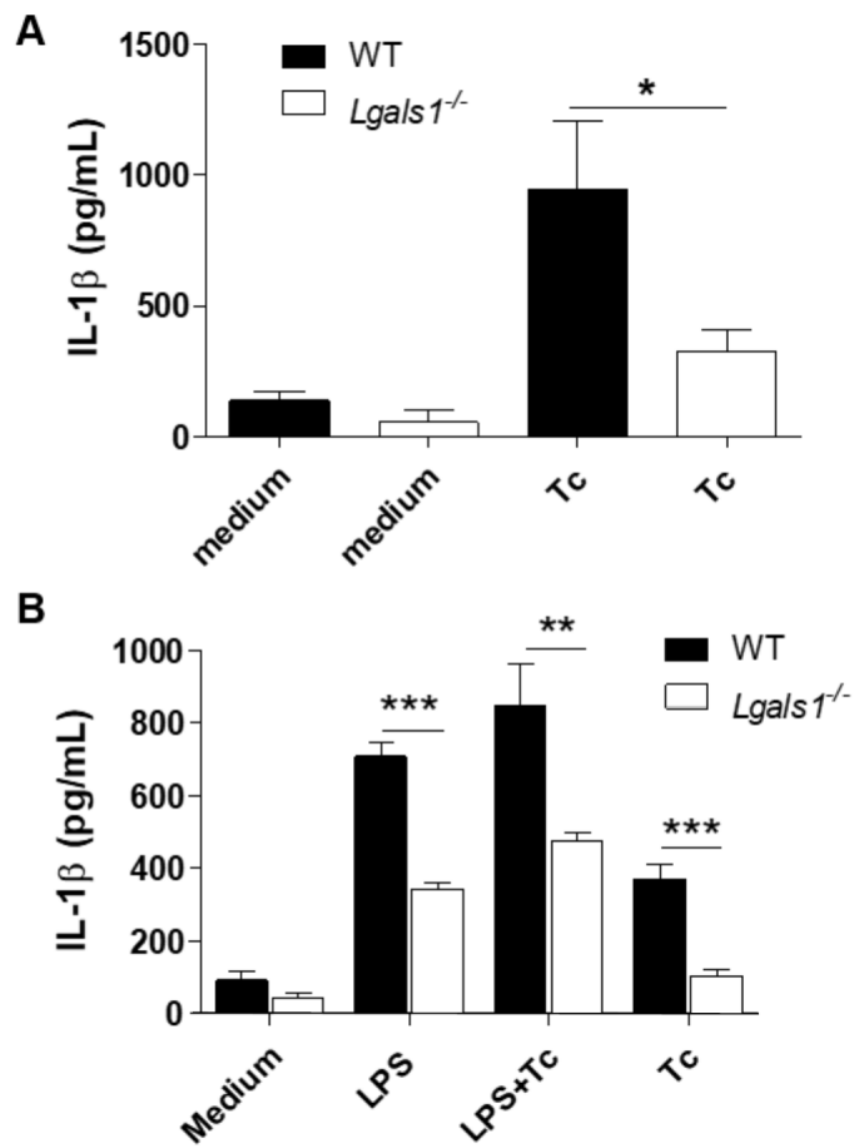
Figure 6

A
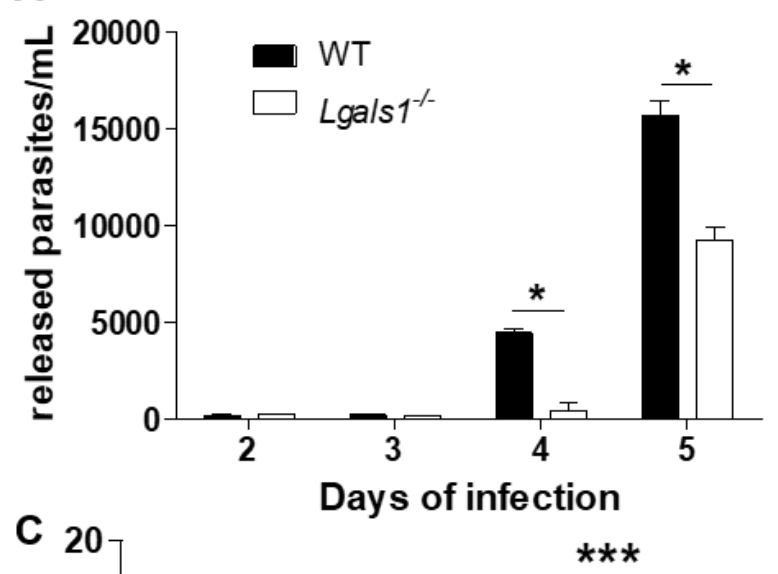

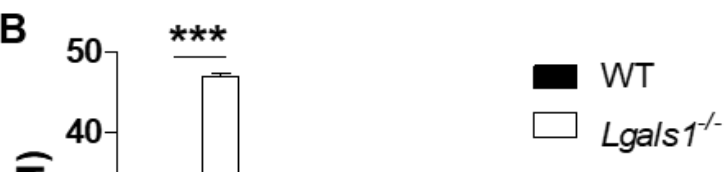

D
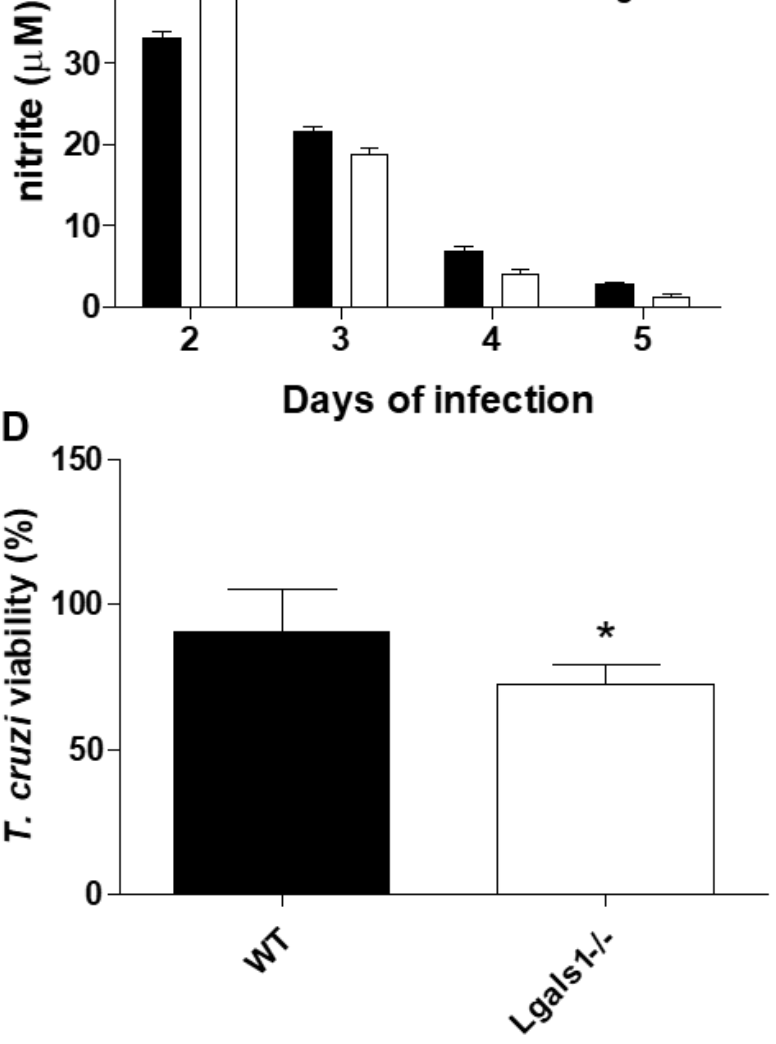

E
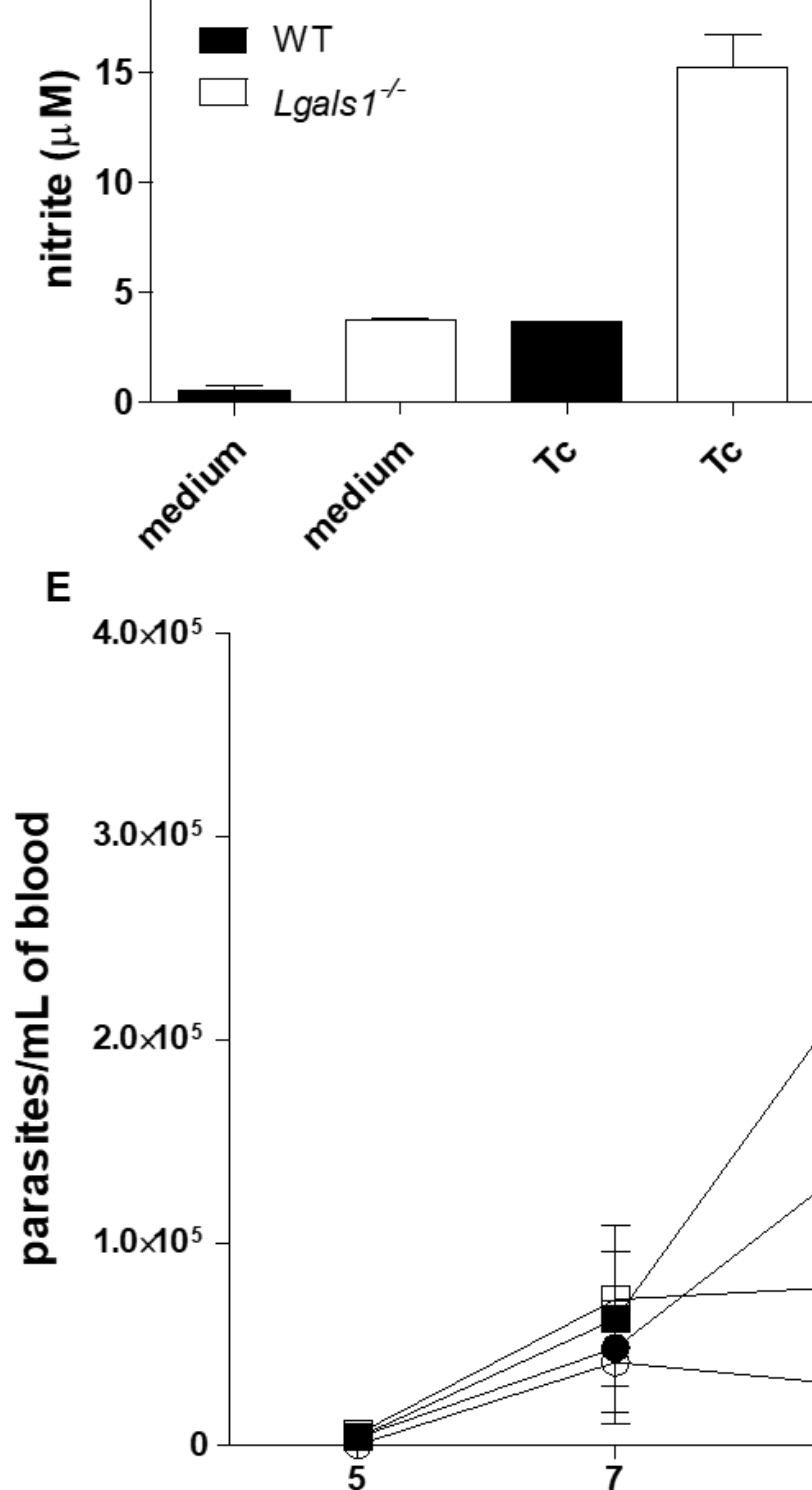

L-NAME

- WT

- WT + L-NAME

- Lgals $1^{-1}$

$\square$ Lgals $1^{-1-}+$ L-NAME

treatment 